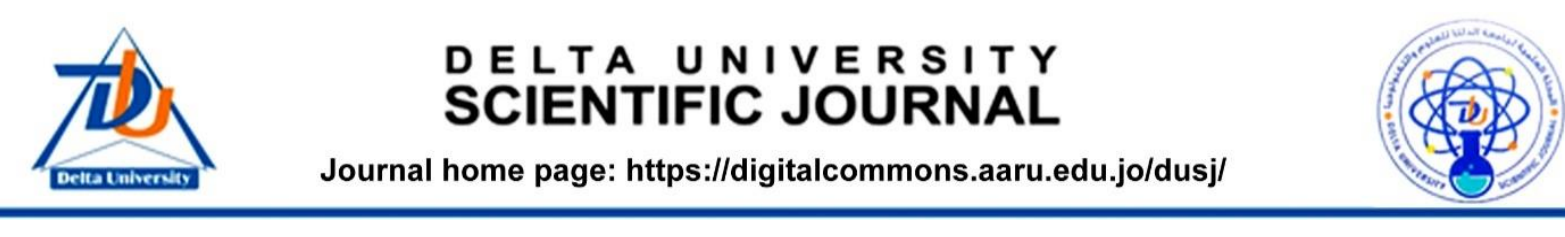

\title{
The role of applying good governance mechanisms to contribute to increasing confidence in integrated reporting in light of the Covid-19 pandemic
}

\author{
Abdul Rahman Mohammed Rashwan, ${ }^{* 1}$ Eitedal Mohammed Alhelou 2 \\ 1 Assistant Professor, Department of Administrative and Financial Sciences, University College of \\ Science and Technology, Gaza, Palestine.
}

2 Assistant Professor, Department of Accounting, College of Business Administration, University of Palestine, Gaza, Palestine.

\section{Keywords:}

1- governance mechanisms

2- integrated reporting

3- the Covid-19 pandemic

4- investment companies

5- Palestine Stock Exchange

\begin{abstract}
The study mainly aimed to identify the role of applying good governance mechanisms to contribute to increasing confidence in integrated reports in light of the Covid 19 pandemic, and to answer questions and test the study hypotheses. Analysis of the results of the applied study and hypothesis testing using the statistical program (SPSS).

The questionnaire was also distributed, after its evaluation and judging by a number of specialists, to the study community consisting of general directors, directors of financial and administrative departments, and heads of financial and administrative departments working in investment companies listed on the Palestine Stock Exchange of (43) employees, and the comprehensive inventory method was used due to the small size the society.

The results of the study showed that the board of directors in the investment companies listed on the Palestine Stock Exchange (PEX) is carefully determining the responsibilities and tasks well to facilitate the task of those in charge of governance to produce integrated reports that are credible, transparent and high quality in light of the Covid-19 pandemic.

The study also recommended trying to take advantage of the benefits achieved by the governance mechanisms and expand their application by the departments of investment companies listed on the Palestine Stock Exchange because of their importance in improving the quality of integrated reports in light of the Covid-19 pandemic.
\end{abstract}

دور تطبيق آليات الحوكمة الرشيدة للمساهمة في زيادة الثقة في التقارير المتكاملة في ظل جائحة كوفيد-

Keywords:

$$
\begin{aligned}
& \text {-1آليات الحوكم } \\
& \text {-2التقارير المتكاملة } \\
& \text { 3جائحة كوفيد-19 } \\
& \text {-4شركات الاستثمار } \\
& \text { 5-5ورصة فلسطين }
\end{aligned}
$$

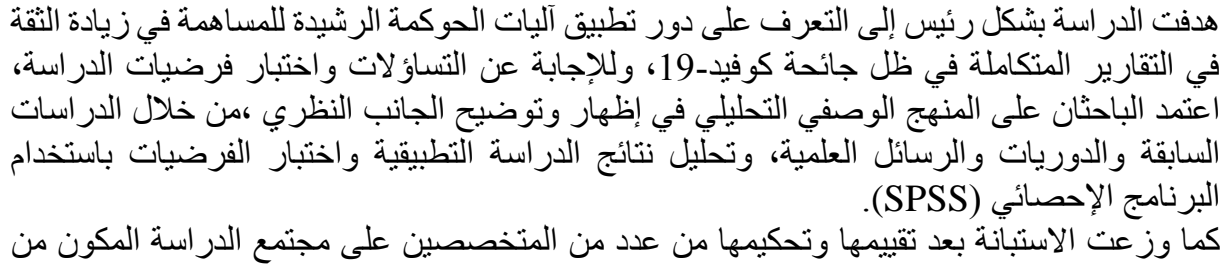


المدر اء العامين، ومدر اء الدو ائر المالية والإدارية، ورؤساء الأقسام المالية و الإدارية العاملين في شركات

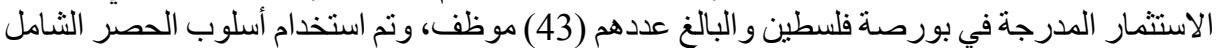

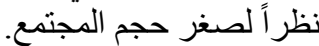

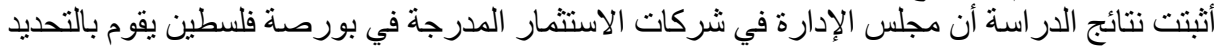

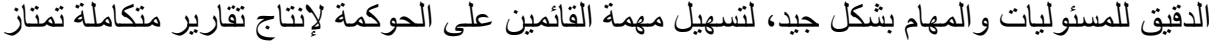

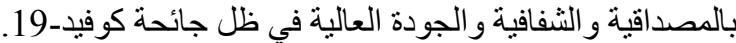

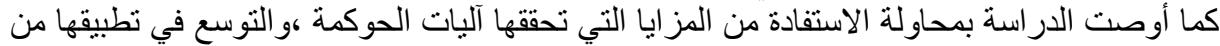

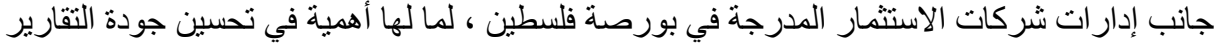
المتكاملة في ظل جائحة كوفيد-19.

قيمة للشركة، وتلبية الاحتباج من المعلومات لكل أصحاب المصالح، مثل المستثمرين و المساهمين. كما زاد الاهتمام بوجود تقارير متكاملة تمتاز بالثقة والمصداقية من أجل فرض مزيد من آليات الحوكمة و المساءلة لحماية الثركات وجذب الاستثمار ات الدولية للسوق المحلية. مما سيجعله عائدا على نمو الثركات وربحيتها، ومع ذللك، فإن الحوكمة الرشيدة أداة لفض لفي الاشتباكات بين أطر اف الثركة، ومشاركة فعالة لجميع الأطر اف، والمساهمة في إدارة أزمة جائحة كوفيد-19، ومن هنا، تظهر أهمية التقارير المتكاملة وما يرتبط بها من أدو ات تساعد على تحقيق مستوى عالٍ من الحوكمة.

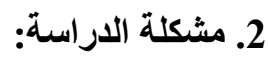
يساعد تطبيق آليات الحوكمة في زيادة الثقة في التقارير المتكاملة، بحيث تكون هذه التقارير شاملة ودقيقة وتقدم المعلومة الملائمة من حيث الوقت المناسب لاتخاذ القرار الرشيد، ونظر اً للتغيرات التي أحدثها جائحة كوفيد-19 في الآونة الأخيرة؛ تز ايد الاهتمام بنطبيق آليات الحوكمة، لإحكام الرقابة على الإدارة ومنعها من استخدام سلطاتها ،وحثها على حماية حقوق المساهمين والمستثمرين و أصحاب المصالح، ووضع أساس محكم وفعال لحوكمة الشركات، ونوفير الثفافية و إعادة الثقة لتعزيز مصداقية المعلومات الواردة بالتقارير المتكاملة، وهنا تبرز لنا أهية تطبيق آليات الحوكمة الرشيدة في تحسين الثقة في التقارير المتكاملة في ظل جائحة كوفيد-19، وفي ضوء ذللك، يمكن صياغة مشكلة الدر اسة في التساؤلات البحثية

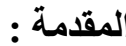

تعد آليات حوكمة الثركات من الأدوات المهمة _في الآونة الأخيرة_ من أجل تحسين جودة التقارير المتكاملة، لزيادة الثقة والاطمئنان بين المساهمين والمستثمرين و أصحاب المصالح، وتلبية احتياجات متخذي القرار ات الداخليين والخارجيين، لهذا نجد ضرورة تمكين دور تطبيق آليات الحوكمة من أجل تحقيق مزيد من الثفافية، وتمكين دور المساءلة عن المسؤوليات المنوحة، حيث تلعب دور اً محورياً في نقل صورة حقيقية للشركة في ظل عدم التأكد المصاحبة لجائحة كوفيد-19، وتعد التقارير المتكاملة إحدى أهم أدو ات إيصال نتائج الأعمال التي نتم من خلال منهجيات تفصح عن النتائج المالية و الأداء. كما تعد حوكمة الشركات إحدى الدعائم الأساسية لنظام التقارير المتكاملة التي تتضمن _إضافة إلى التقارير عن

$$
\text { الأداء المالي_تقرير الحوكمة وغير هما. }
$$

ومن هنا، ظهر دور كبير للتقارير المتكاملة كأداة اتصال موجزة حول الكيفية التي تؤدى بها استر اتيجية الثركة، وحوكمتها و أدائها المالي وآفاقها المستقبلية، والتي تمثل إنتاجاً لتقرير واحد يجمع المعلومات المالية والسردية الواردة في التقرير السنوي للثركة، مع المعلومات غير المالية والسردية التي ترد في تقرير الاستدامة المسؤولية الاجتماعية للشركة. لذلك نجد أن إعداد التقارير المتكاملة في ظل جائحة كوفيد-19 سيؤدي إلى تحسين مستوى وجودة الإفصاح من أجل الاستفادة من تخصيص رأس المال، وتحسين جودة صنع القرار للمستثرين و المساهمين، وتمكين أدوات التقارير المالية الفعالة لتوفير بيانات ذات أثر لكل أصحاب المصالح، وتحقيق نظرة متكاملة في التفكير واتخاذ القرار كجزء من عملية تعظيم 
2. ندرة الدراسات العلمية التي تناولت دور تطبيق آليات الحوكمة الرشيدة للمساهمة في زيادة الثقة في التقارير المتكاملة في ظل جائحة كوفيد-19 ،باعتبار ها من الموضوعات الحديثة والتي تتطلب مزيداً من فن فئن الدر اسات حولها.

3. تستمد الدراسة أهميتها من أهمية تطبيق آليات الحوكمة ودور ها في تحسين جودة التقارير المتكاملة وزيادة الثقة بها. 4. تقديم المساهمة العلمية بدراسة آليات الحوكمة وو اقع تطبيقها في شركات الاستثمار المدرجة في بورصة

$$
\text { فلسطين. }
$$

ب. الأهمية العملية: تتمثل الأهمية العملية في الآتي: 1. تنبيه شركات الاستنمار المدرجة في بورصة فلسطين الاهيه لفهيه

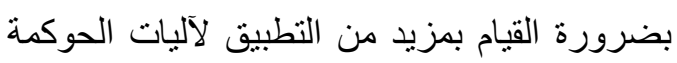

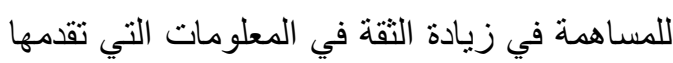
التقارير المتكاملة في ظل جائحة كوفيد- 19. 2. المساهمة في زيادة الوعي لدى شركات الاستثمار المدرجة في بورصة فلسطين بأهمية إعداد التقارير المتكاملة بشكل دوري ؛لما توفره من معلومات تمتاز

$$
\text { بالملاءمة و الموثوقية تعكس أداءها. }
$$

3. تقديم توصيات تفيد من تطبيق آليات الحوكمة لما توفره من تقارير متكاملة تمناز بالمصداقية والثفافية العالية في ظل ظروف عدم التأكد المصاحبة لجائحة كوفيد-

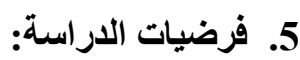
الفرضية الرئيسة: - ابت يوجد دور لتطبيق آليات الحوكمة الرشيدة للمساهمة في زيادة الثقة في التقارير المتكاملة في ظل جائحة كوفيد-

ويتفرع من السؤال الرئيس التساؤلات الفرعية التالية: الفرضية الفرعية الأولى: يوجد دور لتطبيق آليات الحوكمة (مسئوليات مجلس الإدارة) في تحسين جودة

$$
\text { التقارير المتكاملة في جائحة كوفيد-19. }
$$

الفرضية الفرعية الثانية: يوجد دور لتطبيق آليات
الثقة في التقارير المتكاملة في ظل جائحة كوفيد-19؟ ويتفرع من السؤال الرئيس التساؤلات الفرعية التالية: 1. ما دور تطبيق آليات الحوكمة (مسئوليات مجلس الإدارة) في تحسين جودة التقارير المتكاملة في جائحة

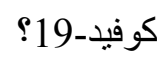
2. ما دور تطبيق آليات الحوكمة (أساس محكم وفعال لحوكمة الشركات) في تحسين جودة التقارير المتكاملة في جائحة كوفبد-19؟ 3. ما دور تطبيق آليات الحوكمة (حماية المساهمين والمستثرين) في تحسين جودة التقارير المتكاملة في جائحة كوفيد-19؟ 4. ما دور ما دور تطبيق آليات الحوكمة (دور أصحاب المصالح) في تحسين جودة التقارير المتكاملة في جائحة كوفيد-19؟ 3. أهداف الدراسة: تهدف الدر اسة إلى تحقيق الأهداف التالية: 1. التعرف على دور تطبيق آليات الحوكمة (مسئوليات مجلس الإدارة) في تحسين جودة التقارير المتكاملة في

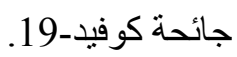
2. التعرف على دور تطبيق آليات الحوكمة (أساس محكم وفعال لحوكمة الشركات) في تحسين جودة التقارير المتكاملة في جائحة كوفيد-19. 3. التعرف على دور تطبيق آليات الحوكمة (حماية المساهمين و المستثمرين) في تحسين جودة التقارير

$$
\text { المتكاملة في جائحة كوفيد-19. }
$$
4. التعرف على دور تطبيق آليات الحوكمة (دور أصحاب

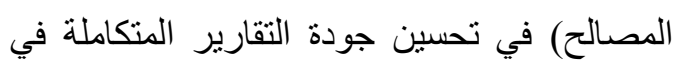

$$
\text { جائحة كوفيد-19. }
$$

4. أهمية الدراسة: تكمن أهمية الدراسة في التالي: أ. الأهمية العلمية: نتمثل الأهمية العلمية في الآتي: 1. سد الفجوة في الدراسات العربية والأجنبية السابقة بتناول متغيرات آليات الحوكمة والتقارير المتكاملة في ظل جائحة كوفيد-19 و التي لم ينت تناولها مجتمعة. 
الفرضية الفرعية الرابعة: يوجد دور لتطبيق آليات الحوكمة (دور أصحاب المصالح) في تحسين جودة التقارير المتكاملة في جائحة كوفيد-19.

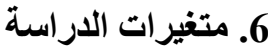

الحوكمة (أساس محكم وفعال لحوكمة الشركات) في

تحسين جودة التقارير المتكاملة في جائحة كوفيد-19. الفرضية الفرعية الثالثة: يوجد دور لتطبيق آليات الحوكمة (حماية المساهمين و المستثمرين) في تحسين جودة التقارير المتكاملة في جائحة كوفيد-19.

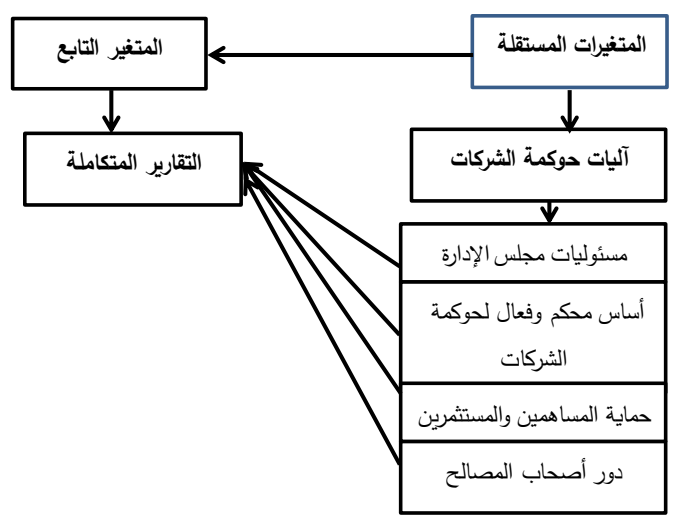

المعلومات المتعلقة بتأثنيرات الجائحة و إدارتها يمثل حلاً للشركات لتلبية نوقعات المستخدمين. علاوة على ذلك ، فإنه يوفر إرشادات للشركات لإعداد التقارير المتكاملة في

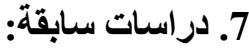

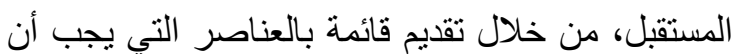
تبين للباحثين من خلال مر اجعة أدبيات الدراسات السابقة؛ تؤخذ في الاعتبار في عملية إدراج المعلومات، ونوصي أن هناك قلة وندرة في الدراسات التي تناولت دور تطبيق الدراسة بالقيام بالعديد من الدراسات المستقبلية حول

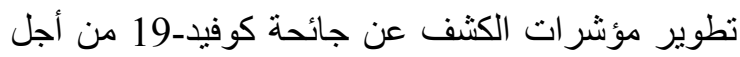
تقديم دليل على مستوى تطبيق التقارير المتكاملة والتحقيق في محددات مستوى المعلومات المتعلقة بالجائحة التي تكثف عنها الشركات. وتناولت دراسة (Shaw, et al, 2020) الحوكمة و التكنولوجيا وسلوك المو اطن في ظل جائحة كوفيد-19 في شرق آسيا في الصين و اليابان وكوريا الجنوبية، وتقدم هذه الدر اسة بعض القو اسم المشتركة و الدروس. وفي حين أن هذه الدول لديها آليات حوكمة مختلفة، فقد أظهرت نتائج الدراسة أن بعض قرارات الحوكمة في البلدان المعنية أحدثت فرقًا في التخفيف من انتشار جائحة كوفيد-19، إلى بلى جانب التضامن المجتمعي القوي والسلوك المجتمعي،

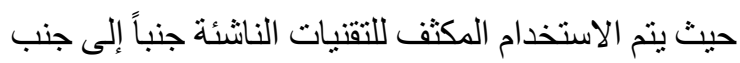
مع العلاج الطبي و الرعاية الصحية لجعل الاستجابة أكثر فعالية، وتقليل مخاطر انتشار الجائحة. و على الرغم من آليات الحوكمة الرشيدة للمساهمة في زيادة الثقة في التقارير المتكاملة في ظل جائحة كوفيد-19، ويمكن سرد

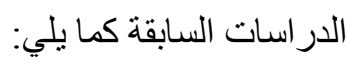
هدفت دراسة (García-Sánchez, 2020) إلى تحديد المعلومات التي يتعين على الثركات إضافتها إلى التقارير المتكاملة في ظل جائحة كو فيد-19، وتظهر نتائج الدر اسة سلسلة من المعلومات، تعتمد أولاً على عناصر المحتوى العام ثم على رؤوس الأموال المحددة التي حددها إطار التقارير المتكاملة، والتي يتعين على الثركات تضمينها في تقارير ها المتكاملة من أجل الحفاظ على المعلومات، لئل

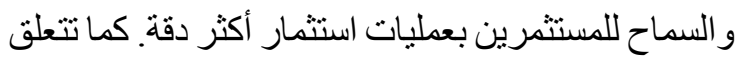
هذه المعلومات بشكل أساسي بوجود وفعالية نظام الوقاية من الجائحة، و العو اقب المالية و غبر المالية للجائحة على لعلى

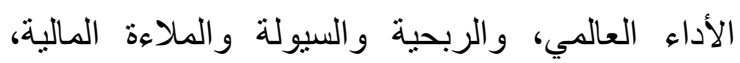
وسياسة الاستثمار و التعاقد وتدريب رأس المال البشري. كما بينت النتائج كيف يمكن أن يكون الكشف عن ولن 
الإفصاح الطوعي للشركات التي تشتجيب لنداء المستثمرين والمنظمين للتركيز بشكل أكبر على استراتيجية الثركات وحوكمتها و أدائها المستقبلي و المخاطر، و التغلب على مشكلة كبيرة. جزء من قيود البيانات المالية التقليدية، وتقديم القضايا الرئيسية التي تتم مناقشتها حالياً فيما يتعلق بتطبيق برنامج التقارير المتكاملة التجريبي، والخصائص الرئيسية للشركات التي قررت الالتزام به، وأظهرت بعض النتائج الأولية التجريبية حول عو امل حوكمة الثركات المرتبطة بالقرار الطوعي لإعداد التقارير المتكاملة وفقًا للإطار الدولي. وبذلك تستخلص الدراسة بعض الاستتناجات حول كيفية ارتباط هيكل وآليات حوكمة الشركات مثل: البيئة القانونية، أو تكوين مجلس الإدارة ،أو هيكل الملكية بسياسات الإفصاح الخاصة بالشركة وقرار اعتماد الإداد

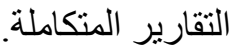
وقد ناقتت دراسة (الحياري ،2017) تقييم أثر تطبيق حوكمة الثركات في تعزيز موثوقية التقارير المالية الصادرة عن الثركات الصناعية المساهمة المدرجة في لهري سوق عمان المالي ، وتكون مجتمع الدر اسة من الوسطاء الماليين والمدراء الماليين ومدققي الحسابات الخارجيين، وتم اعتماد المنهج الوصفي التحليلي و إعداد استبيان تم توزيعه على 125 مفردة لاختبار فرضيات الدراسة

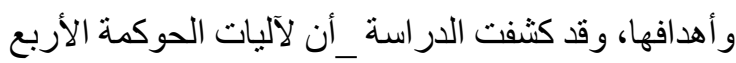
مجتمعة، وكذلك كل منها على انفراد_أثرا ذو دلالة إحصائية على تعزيز موثوقية التقارير المالية الصادرة عن الثركات الصناعية المساهمة العامة المدرجة في سوق عمان المالي ، ولكن مع وجود تفاوت في مدى هذا الأثر، إذ جاءت الآلية الرابعة ( الإفصـاح و الثفافية ) في المركز الأول، في حين جاءت الآلية الثالثة (إدارة المخاطر ) في المركز الر ابع ، وقد أوصت الدر اسة بتحفيز الثركات على إنشاء لجان للحوكمة لمتابعة مدى التزام الثركة بنطبيق مبادىء الحوكمة وآلياتها في الواقع العملي. أما در اسة ( مرتجى ، 2019) فقد ناقشت مدى تطبيق شركات المساهمة العامة المدرجة في بورصة فلسطين
أن الوباء كان عالمياً؛ فإن استجاباته كانت محلية، اعتماداً على السياق الاجتماعي و الاقتصادي و الثقافي. كما تحدثت در اسة (Atkins, et al, 2020) عن الحوكمة المحاسبية والتفكير المتكامل في ظل جائحة كوفيد-19، وتوصلت نتائج الدراسة إلى أن التقارير المتكاملة تعتبر

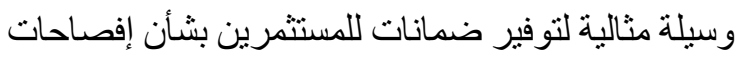
الثركات ذات الأهمية الحاسمة حول إدارة المخاطر . كما مكنها أن تساعد آليات الحوكمة المتطورة أيضاً في المساهمة في زيادة فعالية الثركات وشفافيتها في إدارة مخاطر ومساءلة الثركات عن تأثير ات جائحة كوفيد-19، وتوصي الدراسة أننا بحاجة إلى أطر المحاسبة ولا سيما التقارير المتكاملة، كجزء من إطار حوكمة الثركات الأوسع نطاقاً، ويعد هذا ضروريًا لإتاحة قدر أكبر من

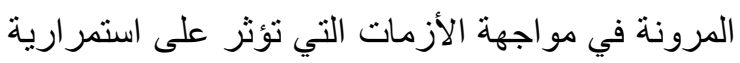

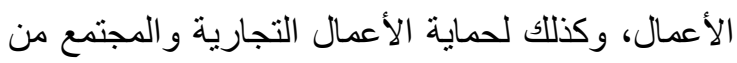
المزيد من الأوبئة وخاصة جائحة كوفيد-19. وقامت دراسة (Foster, 2020) بتقديم نظرة عامة عن تأثير جائحة كوفيد-19 على الثركات من منظور حوكمة الثركات و التخفيف المحتمل لهذا التأثير ، من خلال تطبيق ماتيق المبادئ الواردة في تقرير (King IV) حول حوكمة

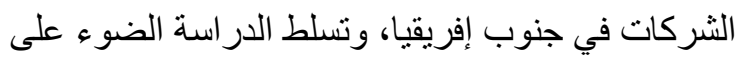
كيفية مر اعاة هذه الفلسفات و المفاهيم و الجو انب الأساسية لحوكمة الثركات، ودمجها في تقرير (King IV) وكيف يمكن لتطبيقها أولاً، التخفيف من تأثير جائحة كوفيد-19 على المنظمات، وثانياً، تمكينها من المضي قدمًا بشكل أفضل لضمان الإستر اتيجية الصحيحة ونموذج الأعمال، وخلق القيمة المستدامة بالطريقة المنلى والأكثر كفاءة الإسنراته بالنظر إلى الوضع الحالي و التوقعات المستقبلية. وتوصلت

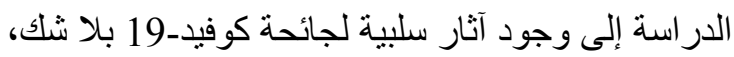
حيث كانت جائحة كوفيد-19 بمثابة حافز وأظهرت بوضوح الحاجة إلى حوكمة الشركات الجيدة، وأن الشركات التي تتمتع بحوكمة مؤسسية جيدة، كان أداؤها أفضل من تللك التي لا تمتلكها. كما ناقتت در اسة (Izzo M.F., Fiori G., 2016) مفهوم التقارير المتكاملة (IR) كأداة مميزة لممارسات 
على استر اتيجية الشركات وحوكمتها و أدائها المستقبلي

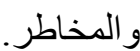

ـ أوجه الاتفاق بين الاراسة الحالية والدراسات السابقة: تتفق الدراسة الحالية مع الدراسات السابقة في جوانب متعددة، أهمها أنها نتناول حوكمة الثركات، وأهم آلياتها، و التقارير المتكاملة.

- أوجه الاختلاف بين الدراسة الحالية والدراسات السابقة: تختلف الدر اسة الحالية عن الدر اسات السابقة في جوانب متعددة أهمها :أنها ربطت بين تطبيق آليات الحوكمة (مسئوليات مجلس الإدارة، أساس محكم وفعال لحوكمة الشركات، حماية المساهمين و المستثمرين، دور أصحاب المصالح) وبين تحسين جودة التقارير المتكاملة في جائحة كوفيد-19، كذلك فإنها تختلف عن الدراسات السابقة في عينة وبيئة الدر اسة، حيث طبقت على شركات قطاع الاستثمار المدرجة في بورصة فلسطين. ـ أوجه الاستفادة من الدراسات السابقة: استفاد الباحثنان من الدراسات السابقة في مجال إثراء الدراسة الحالية ببعض المفاهيم و التعريفات، و النتائج و التوصيات، كذللك تم إعداد الاستبانة ومجالاتها في ضوء الدر اسات السابقة.

\section{الاطار النظري للاراسة:}

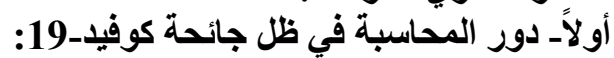
من المعروف أن الأوبئة لها تأثثر واضير واضح ومباشير على طبيعة التقارير المالية للمؤسسات العامة والخاصة، حيث أن كوفيد-19 هو وباء وجائحة عالمية بدأ تأثثر ها واضحاً على الشركات، ولمو اجهة جائحة كوفيد-19 يمكن استخدام الممارسات المحاسبية التي تخفف من تأثثر الجائحة على أداء الثركة مثل: محاسبة القيمة العادلة ،وتسوية الدخل، Peterson, ) و إدارة الأرباح، وتجنب الخسارة 2020) El-Mousawi, Kanso, Kankom 2020) أن تفني كوفيد-19 له أثر كبير على التقارير المالية للشركات، وأن هناك شكوك جو هرية حول ما إذا كانت المنظمات قادرة على الاستمر ارية أم لا، ولذلك فإن ولن الأمر يحتاج إلى إدراج عناصر جديدة في المعايير الدولية

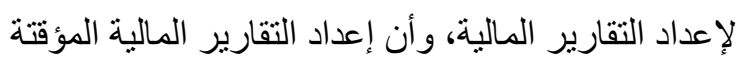

لقو اعد حوكمة الثركات وأثر ذلك على تقييمها المالي، باستخدام مدخل القيمة الاقتصادية المضافة ، نم اتباع المنهج الوصفي التحليلي على مجتمع الدراسة المكون من 49 شركة، واستجابت منها 40 شركة ، وتوصلت الدر اسة إلى أن نسبة التطابق الكلي للمؤشرات مع قو اعد حوكمة الثركات (ء؟\%) وهي نسبة مقبولة من نطبيق قواعد

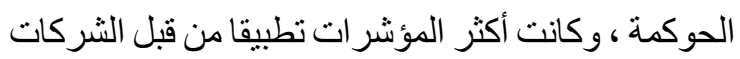
( اللوائح و الأنظمة الداخلية ) يليها ( صلاحيات مجلس

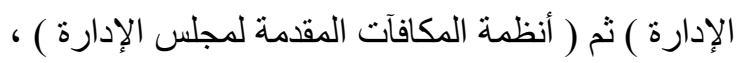
أما أقلها تطبيقا فكانت ( أنظمة التدقيق ) ، حيث سجلت نسبة تطابق منخفضة نسبيا ، كما أظهر قطاع البنوك أكبر درجة نطابق مع قو اعد حوكمة الثركات، يليه قطاع التأمين فالصناعة ، أما أقل القطاعات التزاما فهو قطاع فراع

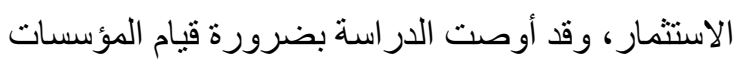
المعنية كسلطة النقد، ووزارة الاقتصاد، وبورصة فلسطين، بدور فاعل في تتظيم دورات تدريبية مكثقة تتخصص في مجال قضايا الحوكمة المتعددة، لارتباطها بكفاءة الثركات وتحسين أدائها المالي، و العمل على زيادة فاعلية دور مجلس الإدارة في اختيار المدراء التنفيذيين وممارسة دور هم في تطبيق القو انين و الأنظمة .

التعقيب على الدراسات السابقة: تناولت الدراسات السابقة الحوكمة والتقارير المتكاملة، و ونها التي تحدثت عن تحديد المعلومات التي يتعين على الشركات إضافتها إلى التقارير المتكاملة في ظل جائحة كوفيد-19، ومنها من تناول الحوكمة و التكنولوجياو سلوك المو اطن في ظل جائحة كوفيد-19 في دول شرق آسيا، و هناك در اسات تحدثت عن الحوكمة المحاسبية و التفكير المتكامل في ظل جائحة كوفيد-19، كما أن هنالك بعض ده الدراسات قامت بتقديم نظرة عامة على نأثير جائحة كوفيد-19 على الثركات من منظور حوكمة الثركات

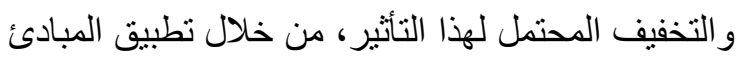
الواردة في تقرير (King IV) حول حوكمة الثركات، و هناك دراسات ناقثت مفهوم التقارير المتكاملة (IR) كأداة مميزة لممارسات الإفصاح الطوعي للشركات الني تستجيب لنداء المستثمرين و المنظمين، للتركيز بشكل أكبر 
المتكاملة في ظل جائحة كوفيد-19، ما ينعكس عليها بالإيجاب بقوة، وذلك من خلال نوفير إطار قوي لنظام معلومات ومساعدته على إنتاج معلومات مالية وغير مالية دقيقة بما يتفق مع سياسات الإفصاح ومتطلباته، وإعداد الخطط لمواجهة المخاطر و إدارتها والتتبؤ بالأزمات، ومنها أزمة جائحة كوفيد- 19 للمحافظة على استمر ارية

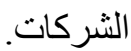

ثالثثاً إجراءات حوكمة الشركات المتبعة لمواجهة جائحة

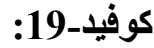
هنالك العديد من إجر اءات حوكمة الثركات التي تم اتباعها لمو اجهة جائحة كوفيد-19 ومنها ما يلي ) IDB Invest,

1. تحديد مسئوليات الإدارة العليا ومدى التزامها بإدارة

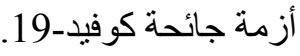
2. القيام بالاتصال الدائم مع الإدارة التنفيذية، واجتماعات مجلس الإدارة الطارئة، وعمليات الاتصال بين موظفي الإدارة التنفيذية ومجلس الإدارة من أجل التدفق الفعال و المستمر للمعلومات، و إعداد التقارير المتكاملة في جائحة

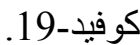

3. مر اجعة واعتماد خطط الطوارئ للموظفين التنفيذين

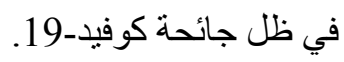

4. الأخذ في الاعتبار تكليف لجنة أزمات متعددة الوظائف

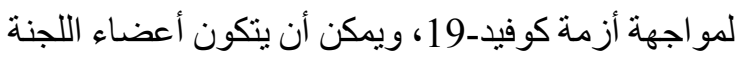
من :عضو مجلس الإدارة ،والإدارة العليا، والمالية، و الموارد البشرية وتكنولوجيا المعلومات ،و القانون. 5. تكليف عمليات التفويض الإداري لتسريع عمليات

الاتصال و اتخاذ القرار ات المتعلقة بجائحة كوفيد-19.

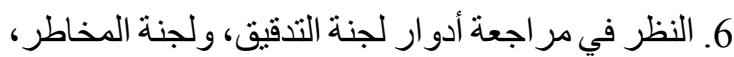
ولجان مجلس الإدارة، واللجان الأخرى لتتولى التواصل و الإشر اف على أزمة كوفيد-19. 7. اعتماد اجتماعات افتراضية عبر الانترنت لمجلس الإدارة و اللجان المختصة بإدارة أزمة كوفيد-19، وزيادة التفاعلات وتبادل الوثائق عبر الوسائل الافتراضية، ومر اجعة متطلبات الاجتماع (النصاب القانوني، الإخطار المسبق بالاجتماع) لكيفية التعامل مع الو اقع الافتر اضي.
له دور في الكثف المبكر والمستمر عن الآثار المترتبة

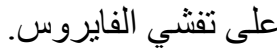

ثانياً- دور الحوكمة الرشيدة في مواجهة جائحة كوفيد:19

لقد أربكت جائحة كوفيد-19 القائمين على مجلس إدارة وحوكمة الثركات وجعلهم في وضع تحد لتجاوز هذه الأزمة، وذلك لأن العمل لم يعد كالمعتاد و إنما يتطلب جهدا كبيرا وتوزيعا للأدوار من قبل لجان حوكمة الثركات للمواجهة و الاستمرارية، وهذا يعني أن مجلس إدارة وحوكمة الثركات يقع عليه كامل المسئولية لتحويل الآثار السلبية إلى الإيجابية، و الخروج من هذه الجائحة بسلام. إن إساس الحوكمة الرشيدة يتمحور في تقسيم مجلس الرسبه الإدارة إلى لجان، بحيث يتم تكليف هذه اللجان بأعمال متكاملة يتم إنجاز هاويتم عرضها في تقارير متكاملة، ومن ثم مناقشتها مع المجلس، ومن أكثر اللجان التي يجب الاهتمام بها في ظل جائحة كوفيد-19 هي: * لجنة التدقيق والمخاطر: و التي تهدف إلى التركيز على الأثر المالي لكوفيد-19 و التحقق منه على الأعمال، ومن خلال هذه اللجنة يتم تقييم التنبؤات المالية، و إعداد اختبارات الملاءة والسيولة، وتخطبط السيناريوهات و البدائل، وتقييم بيئة الرقابة الداخلية، و عليها أيضاً إعداد خطة لمواجهة المخاطر و إدارتها و التنبؤ بالكوارث للمحافظة على استمر ارية الأعمال. * لجنة المكافات: وهي لجنة مهمة لمتابعة أوضاع الموظفين من حيث السلامة في العمل و الصحة و الإجاز ات و الرو اتب و المكافآت و التعويضات في ظل أزمة جائحة كوفيد-19، ويجب عليها إعداد الخطة الإدارية الثاملة لمواجهة الأزمة والاستمرارية في تتفيذ العمل بدون تعطل، وتحقيق تخفيض في التكلفة من خلال متابعة العمل عن بعد وتقسيم الدوام إلى شيفتات أو فترات بحيث ينم تحقيق التباعد الاجتماعي والأخذ بإجراءات الوقاية اللازمة، وفي نفس الوقت يتم إنجاز العمل على أكمل وجه

ضمن هذه الخطة (Escher, 2020). ويتضح للباحثين أن تطبيق آليات حوكمة الثركات يساهم بشكل واضح في إيجاد طريقة مناسبة لإصدار التقارير 
الأداء المختلفة مثل (الأرباح قبل الفوائد، والضرائب، و الإهلاك) في ظل جائحة كوفيد-19، حيث لا تسدح المعايير الدولية لإعداد التقارير المالية بإجراء تعديلات

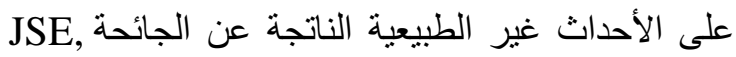

ويمكن تسليط الضوء على العو اقب المالية لجائحة كوفيد19 في الملاحظات على البيانات المالية، حيث سيكون من غير المعتاد أن يتم تغيير البيانات المالية بشكل جوهري ، و يجب الإبلاغ عن الأرباح "المعدلة" بحذر ) Howard,

.(M., 2019

ويرى الباحثان أن وجود تقارير متكاملة تحتوي على معلومات تمتاز بالمصداقية والثفافية قد بيؤثر على لبى استمر ارية الثركة في ظل عدم التأكد الدصاحب لجائحة كوفيد-19، ولتقييم قدرة الثركة على الاستمرارية و المنافسة في ظل الجائحة، يجب الإفصاح عن كيفية إعداد التقارير المتكاملة جنباً إلى جنب مع وجود نظام حوكمة قوي ، حيث يجب أن تفصح الثركة عن جميع الحقائق و الظروف المتعلقة بالبيانات والمعلومات المصاحبة لجائحة كوفيد-19، كما يجب أيضاً مر اعاة منطلبات إعداد

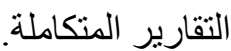

\section{خامساً. اقتراحات لتعزيز التقاريز المتكاملة في ظل} جائحة كوفيل-19:

هناك العديد من الاقتر احات التي يمكن عرضها لتعزيز التقارير المتكاملة في ظل جائحة كوفيد-19 وهي كما يلي: 1. التحول من التركيز الثديد على العو ائد المالية قصبرة الأجل إلى تحسين قيمة رأس المال مع الأخذ في الاعتبار

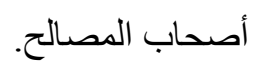

2. تأثير الاستجابة الفورية لجائحة كوفيد-19 على علاقة

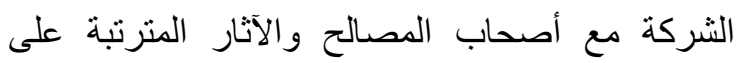
العمليات المستقبلية التي تتبع الأداء عبر مؤشرات متعددة. 3. تطوير معلومات التقارير المتكاملة لتوفر نظرة عن الأداء الذي تم قياسه وفق المؤشرات المناسبة ويحتوي

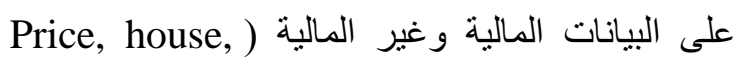

4. التركيز على الإدارة التنفيذية والمدراء الماليين فيما
8. وضع خطة استجابة لإدارة أزمة كوفيد-19 من خلال

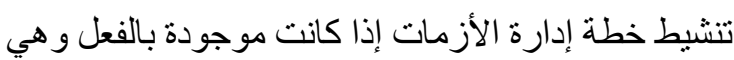
كما يلي: ـ تكليف شخص محدد لمتابعة خطة الاستجابة لإدارة أزمة كوفيد-19 والتواصل مع لجنة الأزمات ،بحيث يكون

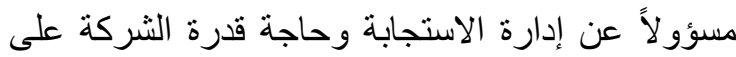

تنفيذ الخطة الاستر اتيجية. ـ تطوير دليل الاستجابة للأزمات، مع تدفقات عملية اتخاذ

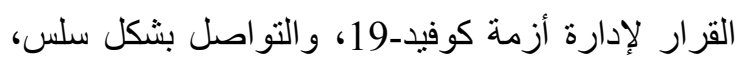
حتى يعرف جميع المشاركين بأدوارهم في إدارة الأزمة.

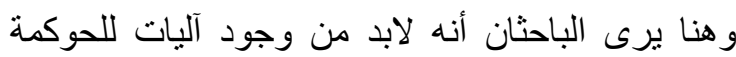

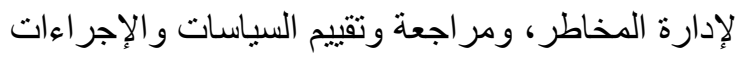
و التدابير المتخذة أثناء إدارة حالة الطوارئ في ظل جائحة كوفيد 19، وفحص قدرة النظام الرقابي القائم على إنى مو اجهتها، إضافة إلى حوكمة التقارير المتكاملة، وذلك بهدف تقييم الأداء المالي و الإداري للشركات لمواجهة حالات الطوارئ و الأزمات المصاحبة لجائحة كوفيد-19. رابعاً. الآثار المترتبة لجائحة كوفيد-19 على التقارير

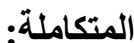
إن ضرورة قيام المكلفين بالحوكمة بلعب دور استباقي في

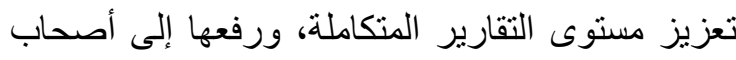
المصالح، وضمان الامتثال للقو انين و اللو ائح يعتبر أمرا

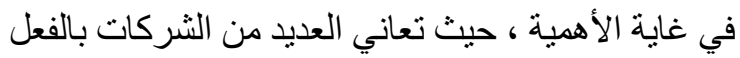
من الإفصاح عن الأحكام والتقديرات الهامة في ظروف

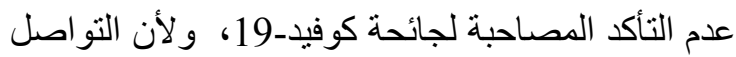
مع المستخدمين و أصحاب المصالح يعد أمر اً بالغ الأهمية للنظر في المخاوف المرتبطة بجائحة كوفيد-19، و إعطاء اهتمام خاص بالإفصاح عن محتويات التقارير المتكاملة نظرًا لتقلبات السوق والتداول غير الطبيعي، فيجب مر اجعة مدى ملاعمة مقاييس القيمة العادلة ، و قد لا تكون الأسعار المدرجة هي القيم العادلة؛ مما يؤدي إلى عرض مدائه إضافي ومنطلبات الإفصاح حسب المعيار الدولي للتقارير المالية رقم 13 ومعيار المحاسبة الدولي رقم 1 (خاصة تللك التي تتعامل مع الأحكام و التقديرات الهامة) التي يتم تفعيلها. كما يجب توخي الحذر عند الإبلاغ عن مقاييس 
مدى فاعلية الأنشطة الرقابية على هذه والتقارير لضمان أي تحريف في ظل عدم التأكد المصاحب لجائحة كوفيد-

الاراسة الميدانية ونتائج اختبار فرضيات للاراسة: تهدف الدراسة الميدانية إلى التكامل بين الإطار النظري

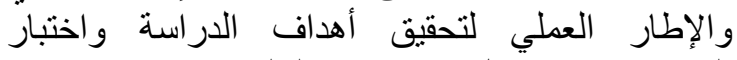
الفرضيات من خلال الإجر اءات التالية:أولاًا منهج اللغراسة:

تم استخدام المنهج الوصفي التحليلي لكونه المنهج المناسب

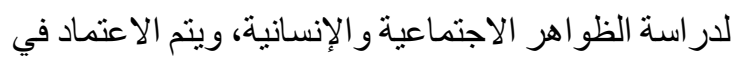
جمع البيانات على المصادر الثنانوية والمصادر الأولية

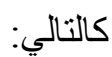
أ. المصادر الثانوية: وتتكون من الكتب والأبحاث و الرسائل العلمية و الدوريات وشبكة الإنترنت. ب. المصادر الأولية: وتتكون من استبانة أعـدت خصيصاً الإنربات

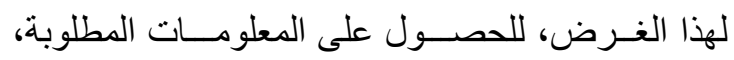
كما يتم استخدم البرنامج الإحصائي SPSS لتحليل الاستبانة، واختبار فرضيات الدراسة.

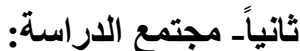

يتكون مجتمع الدراسة من المدراء العامين والماليين والإداريين، ورؤساء الأقسام المالية والإدارية العاملين بشركات الاستثمار المدرجة في بورصة فلسطين والبالغ

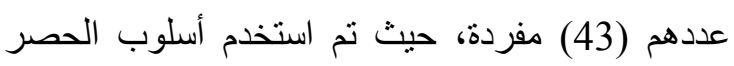
الثنامل نظر اً لصغر حجم المجتمع الطبقي.

ثالثاً أداة الدراسة: تم تقسيم الاستبانة إلى قسمين كما يلي: • • القسم الأول: يتكون من البيانات الديمغر افية لعينة الدراسة، ويتكون من 4 فقرات.

• القسم الثاني: ونم تقسيمه إلى ثلاثة محاور كما يلي: المحور الأول: يوجد دور لتطبيق آليات الحوكمة (مسئوليات مجلس الإدارة) في تحسين جودة التقارير المتكاملة في جائحة كوفيد-19، ويتكون

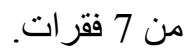
المحور الثاني: يوجد دور لتطبيق آليات الحوكمة (أساس محكم وفعال لحوكمة الثركات) في تحسين جودة التقارير المتكاملة في جائحة كوفيد-19،

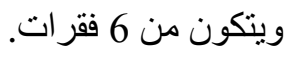

يتعلق بتطوير التقارير المتكاملة. 5. تضمين التقارير المتكاملة على الخطط الإستراتيجية، وتقييم المخاطر وإدارة العمليات التجارية والمالية. 6. يجب الاسترشاد بالتقارير المتكاملة عند اتخاذ القرارات

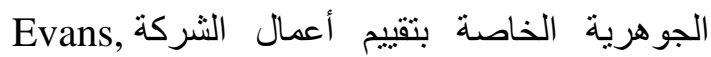
.(2020)

سادساً. دور آليات الحوكمة في تحسين جودة معلومات التقارير المتكاملة في ظل جائحة كوفيد-19: فيما يتعلق بالحوكمة في تحسين جودة معلومات التقارير المتكاملة في ظل جائحة كوفيد-19، يجب أن تقدم التقارير المتكاملة معلومات مفصلة من شأنها أن تسمح للمستخدمين بتقييم فعالية الهيكل المحدد الذي تم إنشاؤه للتعامل مع الجائحة داخل الثركات، ووجود متخصصين مختلفين في مكافحة الجائحة، وأي تغييرات في السياسات و المسؤوليات التي تم تحديدها نتيجة للجائحة، كما يجب على الشركات تقديم المعلومات المتعلقة بحقوق المساهمين و المستثرين و الإفصاح عنها. بالإضافة إلى ذلك، يجب على الثركات تقديم معلومات حول الخطط الاستر اتيجية لتوجيه الثركات، كما يجب أن يكفل المتابعة والمساءلة للإدارة التنفيذية من قبل مجلس الإدارة في ظل جائحة كوفيد-19، كما يجب أيضاً أن ينطوي إطار حوكمة

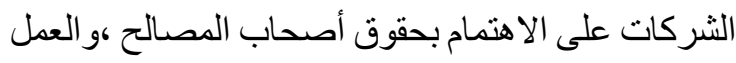
على تشجيع الاتصال بين الثركات وبين أصحاب المصالح، ويجب على الثركات تقديم معلومات حول الإفصاح الدقيق في الوقت الملائم، مع التركيز والاهتمام بالأداء المالي و الإداري للشركات، ورفع مستوى الثفافية، وأن ينو افق هيكل الحوكمة مع الإطار القانوني ويحدد بدقة

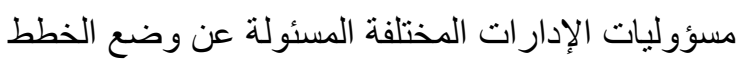
والإجراءات لمواجهة جائحة كوفيد-19، مع توفير Isabel, ) معلومات حول الآفاق المستقبلية ما بعد الجائحة

(et al, 2020 ويستتنج الباحثنان أن لنجاح تطبيق آليات حوكمة الثركات، لابد من فحص فاعلية الأنظمة المالية والإدارية التي لئي تطبقها الثركة، وذللك لتحديد ما إذا كانت التقارير المتكاملة تحتوي على معلومات صحيحة ودقيقة، وتقييم 
هالمور الرابع: يوجد دور لتطبيق آليات الحوكمة

(دور أصحاب المصالح) في تحسين جودة التقارير

المتكاملة في جائحة كوفيد-19.، ويتكون من 6

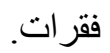

المحور الثالث: يوجد دور لتطبيق آليات الحوكمة

(حماية المساهمين و المستثمرين) في تحسين جودة

التقارير المتكاملة في جائحة كوفيد-19، ويتكون

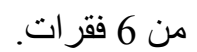

وقد كانت الإجابات عن فقرات المحاور وفق مقياس

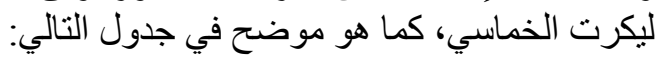

جدول رقم (1) درجات مقياس ليكرت

\begin{tabular}{|c|c|c|c|c|c|}
\hline قليلة جدا & قليلة & متوسطة & كبيرة & كبيرة جدا & التصنيف \\
\hline 1 & 2 & 3 & 4 & 5 & درجة الموافقة \\
\hline
\end{tabular}

استجاب الباحثان لآر اء المحكمين بإجر اء ما يلزم من حذف وتعديل في ضوء المقترحات المقدمة، حيث خرجت

الاستبانة في صورتها النهائية.

2- الصدق البنائي: تم حساب الصدق البنائي لفقر ات الاستبانة على مجتمع الدراسة البالغ عدده (43) مفردة، وذللك بحساب معامل الارتباط بين الدرجة الكلية لكل محور و الدرجة الكلية للاستبانة، ويبين الجدول رقم (2) أن جميع معاملات الارتباط في جميع محاور الاستبانة عند مستوى

دلالة 0.05 حيث إن القيمة الاحتمالية اقل من (0.05).
رابعاً صدق الاستبانة: صدق الاستبانة يعني التأكد من أنها

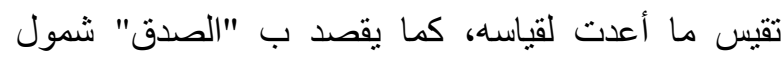
الاستبانة لكل العناصر التي يجب أن تدخل في التحليل من

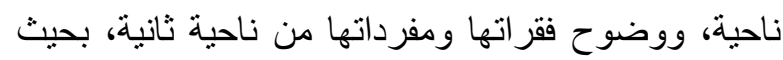
تكون مفهومة لكل من يستخدمها. وقام الباحثان بالتأكد من صدق الاستبانة بطريقتين هما: 1- الصدق الظاهري: حيث تم عرض الاستبانة على مجموعة من المحكمين، نألفت من خمسة من أعضاء الهيئة

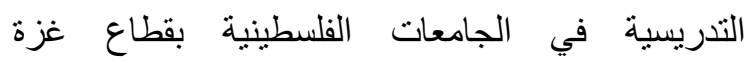
،و المتخصصين في المحاسبة والإدارة و الإحصاء، وقد

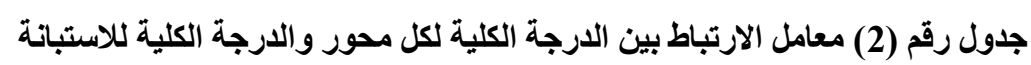

\begin{tabular}{|c|c|c|c|}
\hline القيمة الاحتمالية & معامل الارتباط & المحور & P \\
\hline 0.000 & 0.854 & يوجد دور لتطبيق آليات الحوكمة (مســؤليات مجلس الإدارة) & 1 \\
\hline 0.000 & 0.884 & 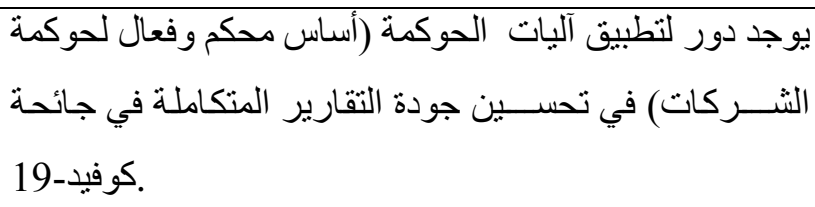 & 2 \\
\hline 0.000 & 0.916 & 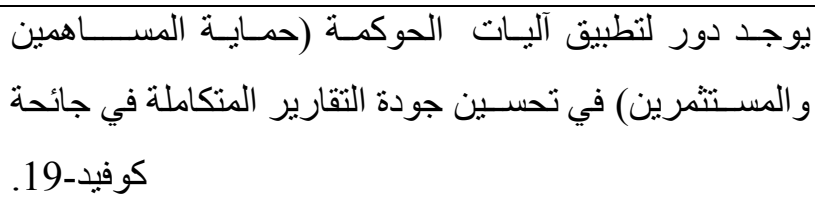 & 3 \\
\hline 0.000 & 0.901 & يوجد دور لتطبيق آليات الحوكمة (دور أصحاب المصالح) في & 4 \\
\hline
\end{tabular}

الاشخاص نفسهم في وقت آخر ، وقد تم استخدام طريقة

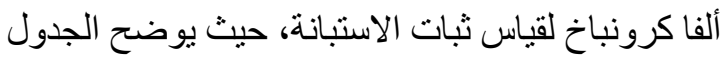

خامساً ثبات الاستبانة: ثبات الاستبانة يعني التاكد من

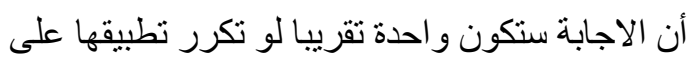


الاستبانة ثبات لقياس كرونباخ ألفا جدول رقم (3) معاملات

\begin{tabular}{|c|c|c|c|c|}
\hline 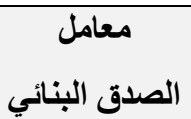 & كرونباخ & العبارات & المحور & b \\
\hline 0.896 & 0.802 & 7 & 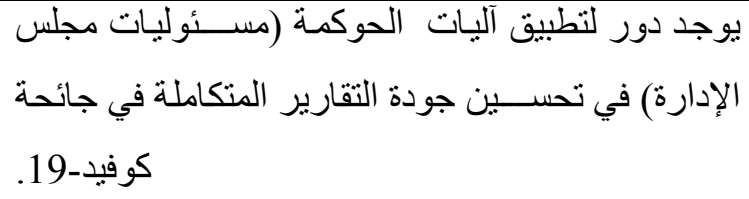 & 1 \\
\hline 0.930 & 0.865 & 6 & 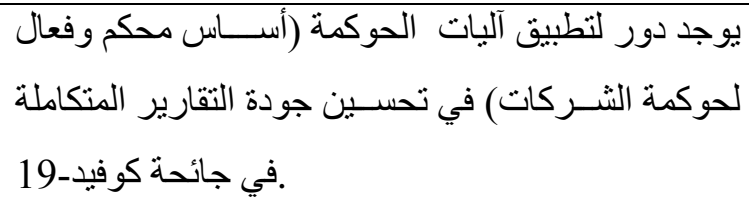 & 2 \\
\hline 0.909 & 0.827 & 6 & 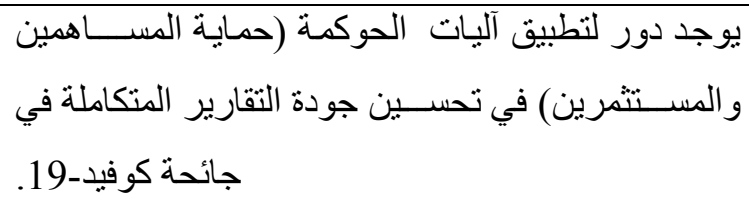 & 3 \\
\hline 0.903 & 0.816 & 6 & 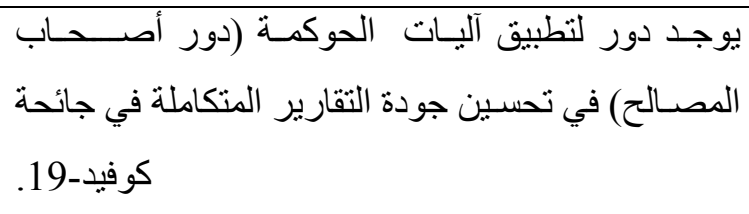 & 4 \\
\hline 0.970 & 0.941 & 25 & الإجمالي & \\
\hline
\end{tabular}

1.اختبار التوزيع الطبيعي (اختبار كولمجروفـ سمرنوف)

استخدم الباحثان اختبار كولمجروف - سمرنوف

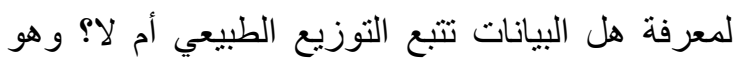
اختبار ضروري في حالة اختبار الفرضيات، لأن معظم الاختبارات المعملية تشترط أن يكون توزيع البيانات طبيعياً، ويوضح الجدول رقم (4) أن قيمة اختبار الجدولية، وكذلك مستوى T T T المسوبة أكبر من قيمة

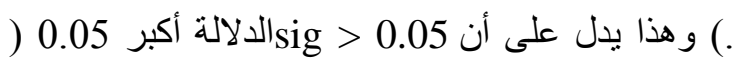
البيانات تتبع التوزيع الطبيعي، ويجب استخدام الاختبار ات

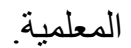

تظهر النتائج المبينة في الجدول رقم (3) أن معاملات ألفا كرونباخ قد تراوحت بين 0.802 - 0.865، وهي معاملات ثبات مرتفعة، كما أن معامل الصدق البنائي قد تر اوح بين 0.896 - 0.930، مما يشير الى تمتع الاستبانة بالثبات و الصدق، وبذلك يكون الباحثنان قد تأكدا من صدق وثبات استبانة الدراسة، مما يجعلهما على ثقة تامة بصحة الاستبانة وصلاحيتها لتحليل النتائج، و الإجابة على أسئلة الدر اسة واختبار فرضياتها. سادساـ تحليل واختبار البيانات:

(1 - Sample Kolmogorov - smirnove)

\begin{tabular}{|c|c|c|c|c|}
\hline المحور & عنوان المحور & الفقرات & $\begin{array}{c}\text { قيمة } \\
\text { T }\end{array}$ & الاحتمالية \\
\hline الر ابع & 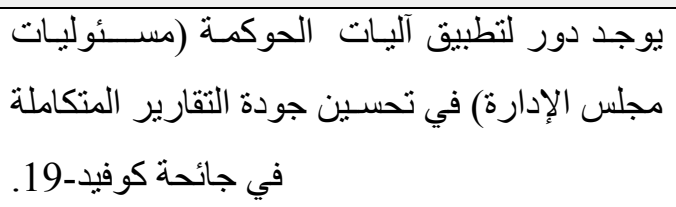 & 7 & 0.803 & 0.422 \\
\hline
\end{tabular}




\begin{tabular}{|c|c|c|c|c|}
\hline الأول & 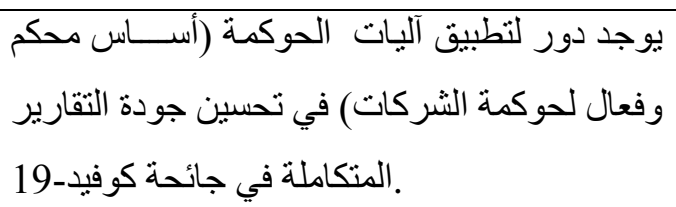 & 6 & 0.867 & 0.459 \\
\hline الثاني & 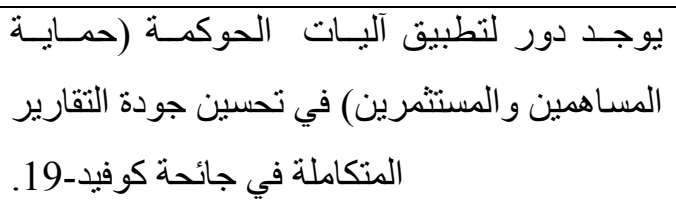 & 6 & 0.829 & 0.431 \\
\hline الثالث & 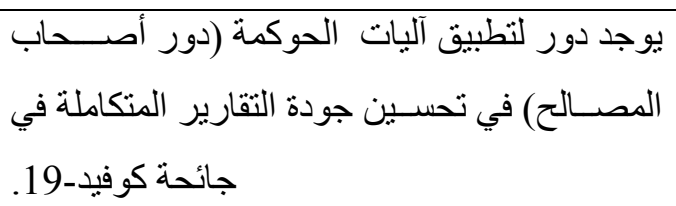 & 6 & 0.810 & 0.429 \\
\hline
\end{tabular}

2. 2 خصائص وسم عات عينة الدراسة:

جدول (5) البيانات الثخصية للعينة

\begin{tabular}{|c|c|c|c|}
\hline النسبة \% & التكرار & البند & \\
\hline 2.3 & 1 & دكتور اه & \multirow{3}{*}{ المؤهل العلمي } \\
\hline 16.3 & 7 & ماجستير & \\
\hline 81.4 & 35 & بكالوريوس & \\
\hline \multicolumn{3}{|l|}{$\% 100$} & \\
\hline 16.3 & 7 & مدير عام & \multirow{3}{*}{ المسمى الوظيفي } \\
\hline 18.6 & 8 & مدير مالي & \\
\hline 16.7 & 7 & مدير إداري & \\
\hline 23.3 & 10 & رئيس قسم مالي & \\
\hline 25.1 & 11 & رئيس قسم إداري & \\
\hline \multicolumn{3}{|r|}{ الإجمالي } & \\
\hline 25.6 & 11 & من 5-10 سنو ات & \multirow{3}{*}{ سنوات الخبرة } \\
\hline 44.2 & 19 & من 11-15 سنة & \\
\hline 30.2 & 13 & أكثر من 15 سنة & \\
\hline \multicolumn{3}{|r|}{ الإجمالي } & \\
\hline 46.5 & 20 & محاسبة & \multirow{3}{*}{ التخصص العلمي } \\
\hline 20.9 & 9 & مالية ومصرفية & \\
\hline 32.6 & 14 & إدارة أعمال & \\
\hline$\% 100$ & 43 & الإجمالي & \\
\hline
\end{tabular}

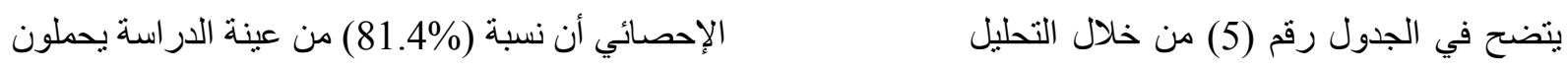


المتوسطة من 11 ــ 10نة، ونسبة (25.6\%) من ذوي

الخبرات المنخفضة من هــــ سنوات.

وكان نسبة (46.5\%) من أفراد العينة من تخصص المحاسبة، بينما كان نسبة (20.9\%) من تخصص العلوم المالية والمصرفية، ونسبة (32.6\%) يحملون تخصص إدارة الأعمال، ويرى الباحثان بأن "المحاسب" هو الفرد المؤهل للقيام بالمهام المالية والإدارية، لذا كان معظم أفر اد العينة من المحاسبين.

سابعاً: التحليل الإحصائي للبيانات واختبار فرضيات

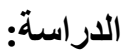

ـ آتبار الفرضية الأولى: "يوجد دور لتطبيق

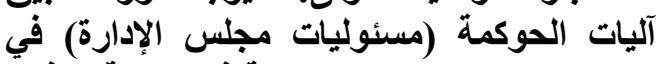
تحسين جودة التقارير المتكاملة في جائحة كوفيدات

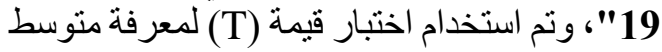

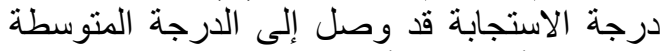
و هي (3) أو لا لدى أفر اد العينة، والنتائج موضحة المنة

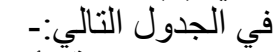

جدول رقم (6) التحليل الإحصائي الفقرات الفرضية الأولى دلى

\begin{tabular}{|c|c|c|c|c|c|c|c|}
\hline الترتيب & $\begin{array}{l}\text { الاحتمالية } \\
\text { القيمة } \\
\text { ).sig( }\end{array}$ & Tتيمة & النسبي & الانعراف & الحسابي & العبـــــــــــــــارات & p \\
\hline 5 & 0.000 & 15.99 & 82.79 & 0.47 & 4.14 & 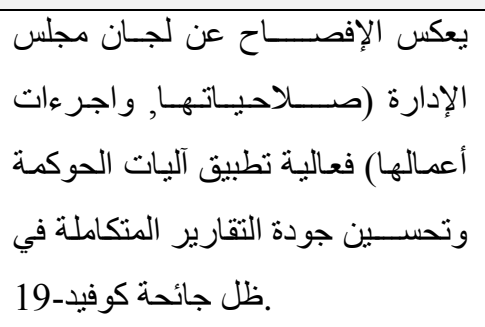 & 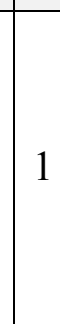 \\
\hline 7 & 0.000 & 11.09 & 81.40 & 0.63 & 4.07 & 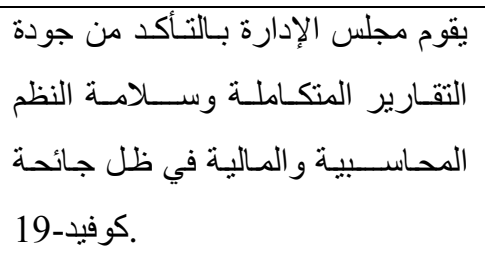 & 2 \\
\hline 5 & 0.000 & 12.43 & 82.79 & 0.60 & 4.14 & 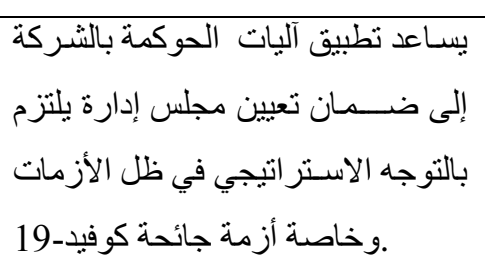 & 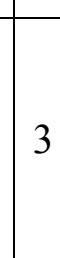 \\
\hline 4 & 0.000 & 11.71 & 83.72 & 0.66 & 4.19 & 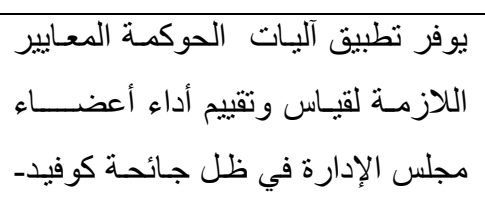 & 4 \\
\hline
\end{tabular}

درجة البكالوريوس، ونسبة (16.3\%) يحملون درجة الماجستير، ونسبة (2.3\%) يحملون درجة الدكتور اه، ولعل ذلك يرجع إلى طبيعة عمل العينة المستجيبة، فهم يتبعون الأقسام المالية والإدارية، وبالتالي فإن الأقسام المالية والإدارية بحاجة إلى مؤهلات علمية مناسبة في الغالب من حملة درجة البكالوريوس.

وكان نسبة (25.1\%) من عينة الدراسة من رؤساء الأقسام الإدارية، بينما كان نسبة (23.3\%) هم من رؤساء الأقسام المالية، ونسبة (18.6\%) هم من مدراء الدو ائر الماليين، بينما كانت نسبة (16.7\%) من المدراء الإداريين، كما كانت نسبة (16.3\%) هم من مدراء المدراء العامين وهذا يعكس طبيعة الدوائر المالية و الإدارية و عملها.

وكان نسبة(r • • \%\%) لديهم خبرات مرتفعة من

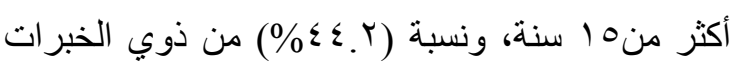




\begin{tabular}{|c|c|c|c|c|c|c|}
\hline & & & & & & 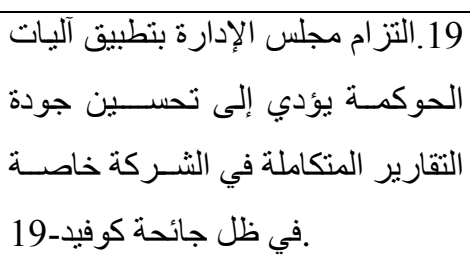 \\
\hline 2 & 0.000 & 9.61 & 84.65 & 0.84 & 4.23 & تلطبيق الثـــركة لالكيات الحوكمة يؤدي \\
\hline 3 & 0.000 & 9.52 & 84.19 & 0.83 & 4.21 & 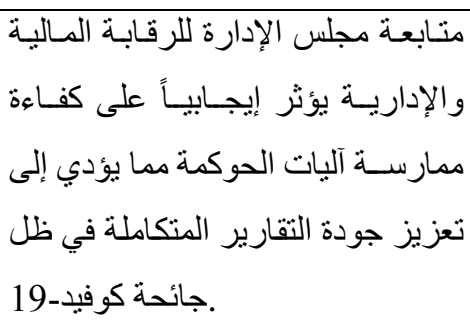 \\
\hline 1 & 0.000 & 14.43 & 86.98 & 0.61 & 4.35 & 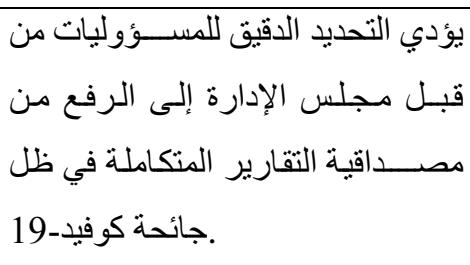 \\
\hline - & 0.000 & 17.07 & 83.79 & 0.46 & 4.19 & جميع الفقرات معاً \\
\hline
\end{tabular}

، وبوزن نسبي 4.14)على أقل متوسط حسابي بلغ ( \%) وهو أكبر من قيمة الوزن النسبي المحايد 79.82 12. 43) المحسوبة بساوي (60\%)، وقيمة اختبار( ) الجدولية والتي تساوي (1.95)، Tو هي أكبر من قيمة (

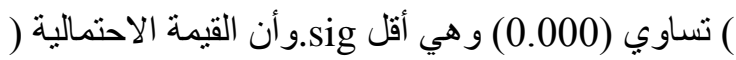
من (0.05)، و هذا يدلل على أن مجلس الإدارة في شركات الاستثمار المدرجة في بورصة فلسطين يهتم بسلامة النظم المحاسبية والإدارية والمالية التي تنتج التقارير المتكاملة للتأكد من جودتها في ظل جائحة كوفيد-19.

ـ تبين أن المتوسط الحسابي لجميع فقرات المجال يساوي \%83\%) وهو أكبر من قيمة 79، الوزن النسبي (4.19)(

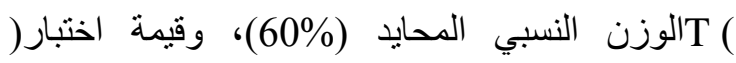

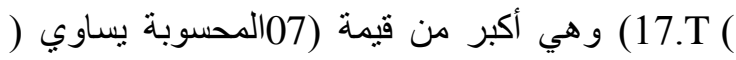
الجدولية والتي تساوي (1.95)، وأن القيمة الاحتمالية

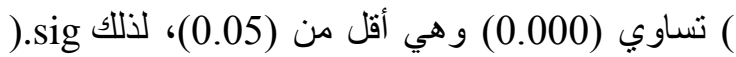

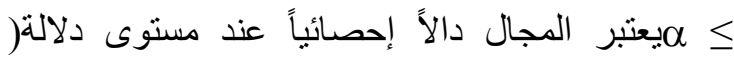

يستتنج الباحثان من الجدول السابق رقم (6) ما يلي: - إن الفقرة رقم (7) التي تتص على "يؤدي التحديد الدقيق للمسؤوليات من قبل مجلس الإدارة إلى الرفع من مصداقية التقارير المتكاملة في ظل جائحة كوفيد-19" قد حصلت

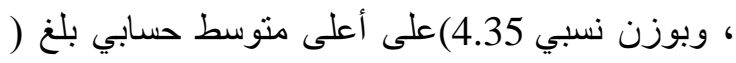
\%86. 14. 43) المحسوبة يساوي (60\%)، وقيمة اختبار( ) الجدولية والتي تساوي (1.95)، Tو هي أكبر من قيمة ( ) تساوي (0.000) و هي أقل (sig.و أن القيمة الاحتمالية ( من (0.05)، و هذا يدلل على أن مجلس الإدارة في شركات الاستثمار المدرجة في بورصة فلسطين يحدد المسئوليات و المهام بشكل جيد لتسهيل مهمة القائمين على الحوكمة لإنتاج تقارير منكاملة تمناز بالجودة العالية في ظل جائحة كوفيد-19.

- إن الفقرة رقم (3) التي تتص على "يقوم مجلس الإدارة بالتأكد من جودة التقارير المتكاملة وسلامة النظم المحاسبية و المالية في ظل جائحة كوفيد-19" قد حصلت 
بشكل فعال أعمال الإدارة التنفيذية من قبل مجلس الإدارة، وتتم مساءلة مجلس الإدارة من قبل المساهمين.

لم تتفق نتائج هذه الفرضية مع نتائج أي در اسة، كما تختلف (تنائج هذه الفرضية مع دراسة كلٍ من GarcíaSánchez, 2020) ‘(Shaw, et al, 2020 ) ( )Atkins, et al, 2020) ‘(Foster, 2020) ‘(Izzo M.F., Fiori G., 2016.(

- اختبار الفرضية الثانية: "يوجد دور لتطبيق آليات الحوكمة (أساس محكم وفعال لحوكمة الثركات) في تحسين جودة التقارير المتكاملة في جائحة كوفيد-19"، ) لمعرفة ما إذا كان متوسط Tوتم استخدام اختبار قيمة ( درجة الاستجابة قدوصل إلى الدرجة المتوسطة وهي (3) أو لا لدى أفراد العينة، والنتائج موضحة في الجدول

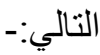

)، مما يدل على أن مستوى الاستجابة لهذا المجال 0.05 قد زاد عن الدرجة المتوسطة وهي (3)، وهذا يعني أن هناك مو افقة من قبل أفر اد العينة على فقر ات هذا المجال. ـ ـتيجة الفرضية: ووفقاً للجدول السابق، وتحليل البيانات

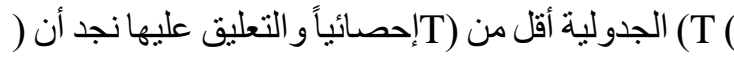
المحسوبة، مما يعني رفض الفرضية العدم، وقبول الفرضية البديل الذي ينص على أنه "يوجد دور لتطبيق آليات الحوكمة (مسئوليات مجلس الإدارة) في تحسين جودة التقارير المتكاملة في جائحة كوفيد-19". ويرى الباحثان أن مو افقة أفراد العينة بدرجة كبيرة على لى لئل أنه "يوجد دور لتطبيق آليات الحوكمة (مسئوليات مجلس الإدارة) في تحسين جودة التقارير المتكاملة في جائحة كوفيد-"19، وهذا يدلل على أن شركات الاستثمار المدرجة في بورصة فلسطين تطبق آليات الحوكمة وتتابع

جدول رقم (7) التحليل الإحصائي لفقرات الفرضية الثانية

\begin{tabular}{|c|c|c|c|c|c|c|c|}
\hline الترتيب & $\begin{array}{l}\text { الاحتمالية } \\
\text { القيمة } \\
\text { ).sig( }\end{array}$ & قاختبار T & 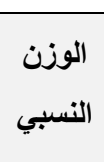 & المعياري & 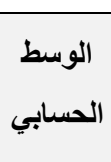 & العبــــــــــــــــارات & r \\
\hline 1 & 0.000 & 12.06 & 86.05 & 0.71 & 4.30 & 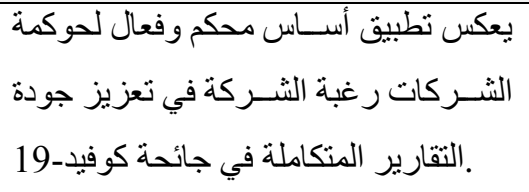 & 1 \\
\hline 3 & 0.000 & 7.51 & 80.00 & 0.87 & 4.00 & 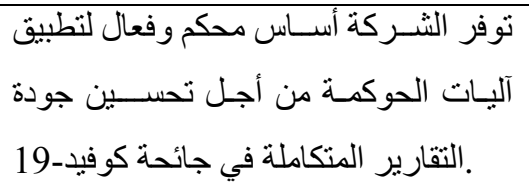 & 2 \\
\hline 4 & 0.000 & 7.99 & 79.53 & 0.80 & 3.98 & 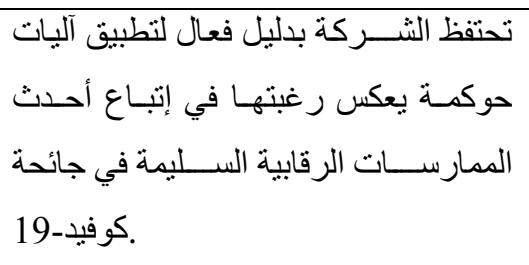 & 3 \\
\hline 6 & 0.000 & 6.00 & 77.21 & 0.94 & 3.86 & 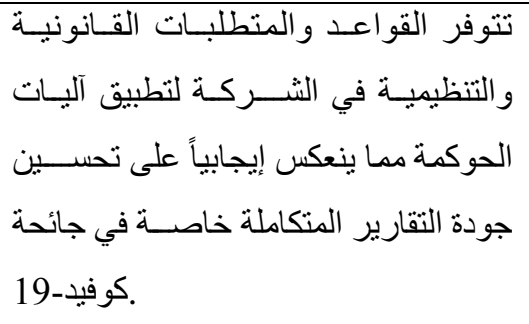 & 4 \\
\hline 2 & 0.000 & 9.52 & 81.40 & 0.74 & 4.07 & 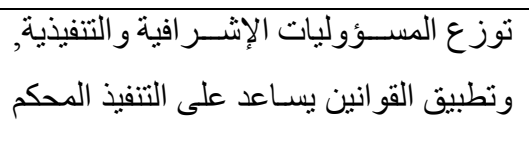 & 5 \\
\hline
\end{tabular}




\begin{tabular}{|c|c|c|c|c|c|c|c|}
\hline & & & & & & 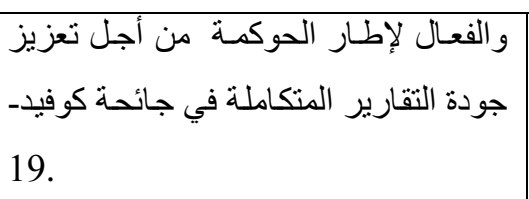 & \\
\hline 5 & 0.000 & 6.85 & 78.14 & 0.87 & 3.91 & 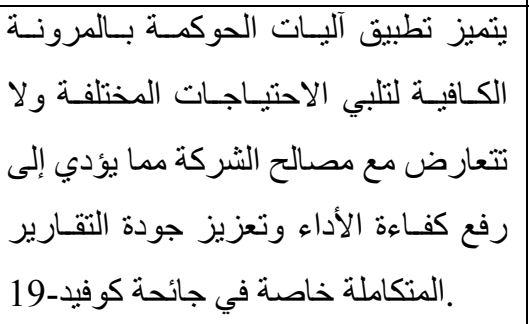 & 6 \\
\hline - & 0.000 & 10.49 & 80.39 & 0.64 & 4.01 & جميع الفقرات معاً & \\
\hline
\end{tabular}

أجل زيادة جودة التقارير المتكاملة في ظل جائحة

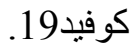

ـ تبين أن المتوسط الحسابي لجميع فقرات المجال يساوي

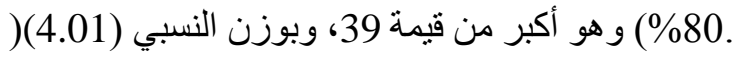

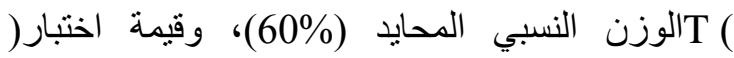
10.T ( الجدولية والتي تساوي (1.95)، وأن القيمة الاحتمالية ) تساوي (0.000) وهي أقل من (0.05)، لذلك (2. ).sig

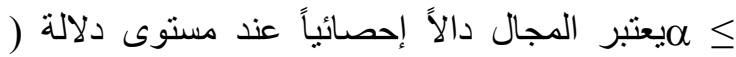
)، مما بدل على أن مستوى الاستجابة لهذا المجال 0.05 قد زاد عن الدرجة المتوسطة وهي (3)، وهذا يعني أن هناك مو افقة من قبل أفراد العينة على فقرات هذا المجال. ـ نتيجة الفرضية: ووفقاً للجدول السابق وتحليل البيانات (T) الجدولية أقل من (T) (إحصائياً والتعليق عليها نجد أن (T) ( المحسوبة، مما يعني رفض الفرضية العدم، وقبول الفرضية البديل الذي ينص على أنه "يوجد دور لتطبيق آليات الحوكمة (أساس محكم وفعال لحوكمة الثركات) في لي لئل تحسين جودة التقارير المتكاملة في جائحة كوفيد-19". ويرى الباحثان أن مو افقة أفراد العينة بدرجة كبيرة على أنه يوجد دور لتطبيق آليات الحوكمة (أساس محكم وفعال لحوكمة الثركات) في تحسين جودة التقارير المتكاملة في جائحة كوفيد-19، وقد يعزى ذللك إلى أن شركات الاستثمار المدرجة في بورصة فلسطين توفر الأسس

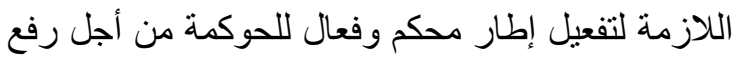
مستوى الثفافية، كما ينو افق هيكل الحوكمة مع الإطار
يستنتج الباحثان من الجدول السابق رقم (7) ما يلي: -- إن الفقرة رقم (1) التي تنص على "يعكس تطييق أساس محكم وفعال لحوكمة الثركات رغبة الثركة في تعزيز جودة التقارير المتكاملة في جائحة كوفيد-19" قد حصلت ، وبوزن نسبي 4.30)على أعلى منوسط حسابي بلغ (

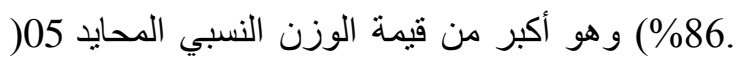
06.12) المحسوبة يساوي (60\%)(60\%)، وقيمة اختبار( ) الجدولية و التي تساوي (1.95)، Tو هي أكبر من قيمة ( ) تساوي (0.000) و هي أقل (sig.وأن القيمة الاحتمالية (1) ( من (0.05)، وهذا يدلك على أن شركات الاستثمار المدرجة في بورصة فلسطين تقوم بتطبيق آليات محكمة وفعالة للحوكمة من أجل تحسين وتعزيز جودة التقارير المتكاملة في ظل جائحة كو فيد19. -- إن الفقرة رقم (4) التي تتص على "تتوفر القواعد و المتطلبات القانونية و التنظيمية في الثركة لتطبيق آليات الحوكمة مما ينعكس إيجاباً على تحسين جودة التقارير المتكاملة خاصة في جائحة كوفيد-19" قد حصلت على ، وبوزن نسبي 3.86)أقل متوسط حسابي بلغ ( )

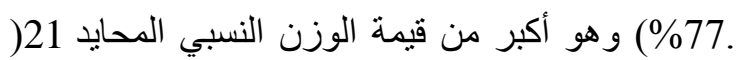

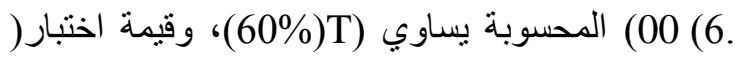
) الجدولية و التي تساوي (1.95)، Tو هي أكبر من قيمة (

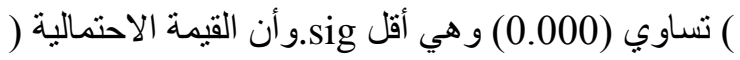
من (0.05)، وهذا يدلل على أن شركات الاستنمار المدرجة في بورصة فلسطين تتبع قواعد ومتطلبات قانونية وتنظيمية للمساعدة في تطبيق آليات الحوكمة من 
- اختبار الفرضية الثالثة: "يوجد دور لتطبيق آليات الحوكمة (حماية المساهمين والمستثمرين) في تحسين جودة التقارير المتكاملة في جائحة كوفيد-19"، وتم ) لمعرفة متوسط درجة الاستجابة Tاستخدام اختبار قيمة ( قد وصل إلى الدرجة المتوسطة وهي (3) أو لا لدى أفر اد العينة، و النتائج موضحة في الجدول التالي:-
القانوني ويحدد بدقة مسؤوليات الإدارات المختلفة المسئولة عن الإشر اف والرقابة.

لم تتفق نتائج هذه الفرضية مع نتائج أي در اسة، كما تختلف ) تتائج هذه الفرضية مع دراسة كلٍ من GarcíaSánchez, 2020) ‘(Shaw, et al, 2020 ) )Atkins, et al, 2020) ‘(Foster, 2020) ‘(Izzo M.F., Fiori G., 2016.(

جدول رقم (8) التحليل الإحصائي لفقرات الفرضية الثالثة

\begin{tabular}{|c|c|c|c|c|c|c|}
\hline الترتيب & 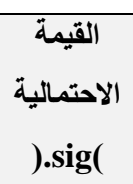 & Tقيمة Tتبار & النسبي & الانحراف & الحسابي & العبـــــــــــــــارات \\
\hline 4 & 0.000 & 11.42 & 85.58 & 0.734 & 4.28 & 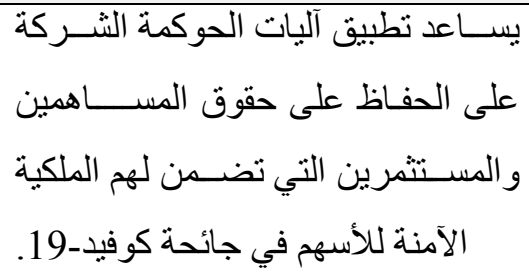 \\
\hline 5 & 0.000 & 12.51 & 85.12 & 0.658 & 4.26 & 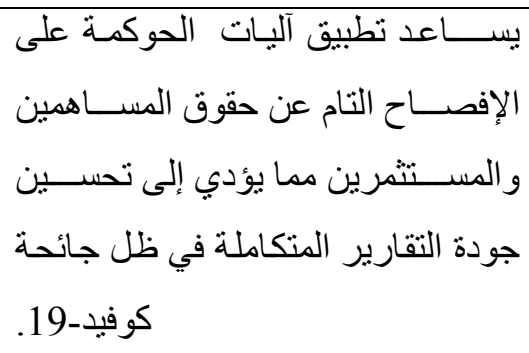 \\
\hline 6 & 0.000 & 12.40 & 83.72 & 0.627 & 4.19 & 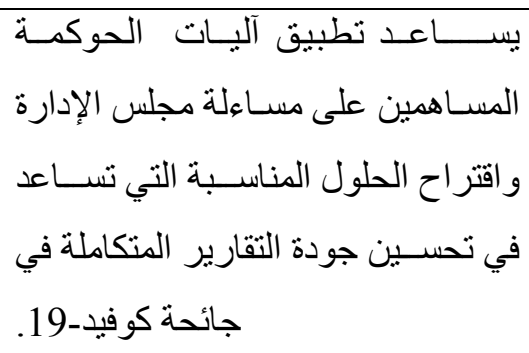 \\
\hline 2 & 0.000 & 7.23 & 79.53 & 0.886 & 3.98 & 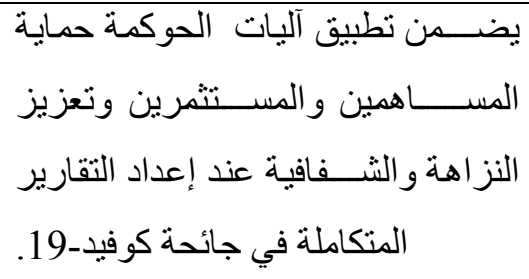 \\
\hline 3 & 0.000 & 9.56 & 81.86 & 0.750 & 4.09 & 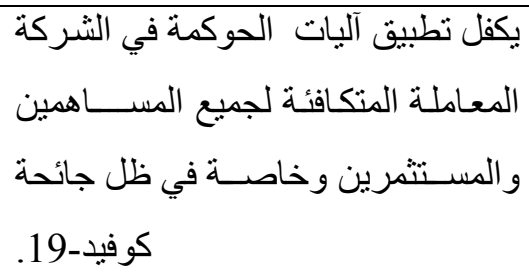 \\
\hline
\end{tabular}




\begin{tabular}{|c|c|c|c|c|c|c|c|}
\hline 1 & 0.000 & 7.02 & 79.53 & 0.913 & 3.98 & 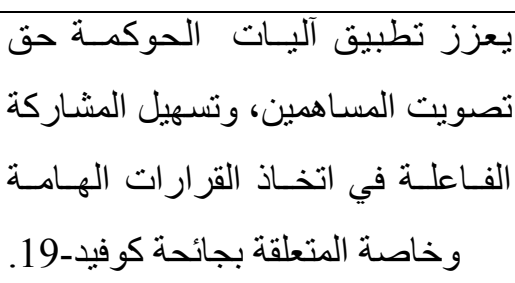 & 6 \\
\hline - & 0.000 & 13.13 & 82.56 & 0.563 & 4.13 & جميع الفقرات معاً & \\
\hline
\end{tabular}

الوزن النسبي المحايد (60\%)، وقيمة اختبار( ) (

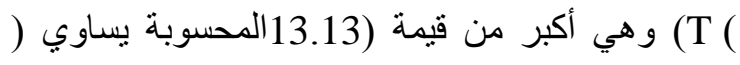
الجدولية والتي تساوي (1.95)، وأن القيمة الاحتمالية

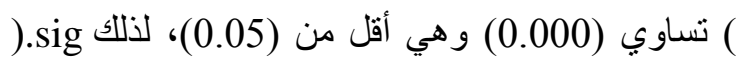

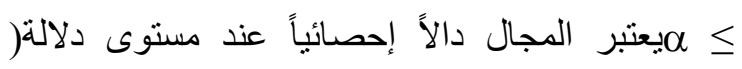
)، مما يدل على أن مستوى الاستجابة لهذا المجال 0.05

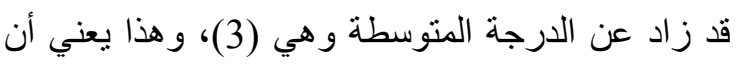
هنالك مو افقة من قبل أفر اد العينة على فقرات هذا لـونه المجال. ـ نتيجة الفرضية: ووفقاً للجدول السابق وتحليل البيانات

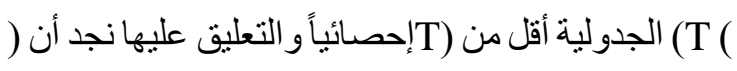
المحسوبة، مما يعني رفض الفرضية العدم، وقبول الفرضية البديل الذي ينص على أنه "يوجد دور لتطبيق

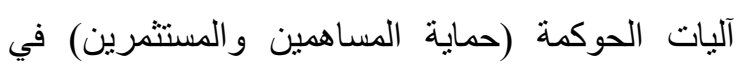
تحسين جودة التقارير المتكاملة في جائحة كوفيد-19".

ويرى الباحثان أن موافقة أفراد العينة بدرجة كبيرة على أنه يوجد دور لتطبيق آليات الحوكمة (حماية المساهمين والمستثمرين) في تحسين جودة التقارير المتكاملة في جائحة كوفيد-19، وقد يعزى ذلك إلى أن شركات الاستثمار المدرجة في بورصة فلسطين تقوم بتطبيق آليات الحوكمة من أجل حماية المساهمين والمستثمرين التي تضمن الملكية الآمنة للأسهم،

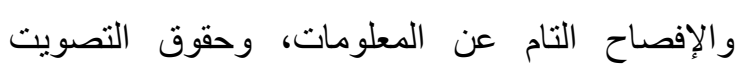
و غير ها من الحقوق وخاصة في ظل جائحة كورونا.

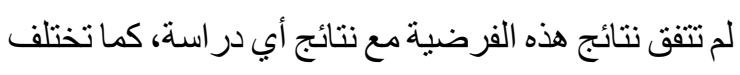
(GarcíaSánchez, 2020) (Shaw, et al, 2020 ) )Atkins, et al, 2020) ‘(Foster, 2020) ‘(Izzo M.F., Fiori G., 2016.(
يستنتج الباحثان من الجدول السابق رقم (8) ما يلي: - إن الفقرة رقم (5) التي تنص على "يعزز تطبيق آليات

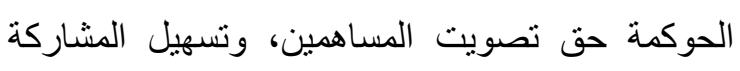
الفاعلة في اتخاذ القرار ات الهامة وخاصة المتعلقة بجائحة كوفيد-19" قد حصلت على أعلى منوسط حسابي بلغ

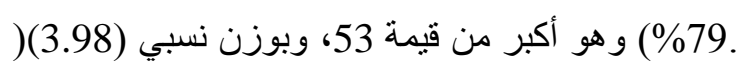
الوزن النسبي المحايد (60\%) (

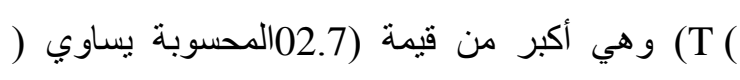
الجدولية والتي تساوي (1.95)، وأن القيمة الاحتمالية

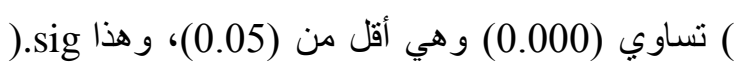
يدلل على أن شركات الاستثمار المدرجة في بورصة فلسطين تهنم بتطبيق آليات الحوكمة لتسهيل عملية اتخاذ القرار ات في ظل عدم التأكد لجائحة كوفيد-19. - إن الفقرة رقم (3) التي تتص على "يساعد تطبيق أليات الحوكمة المساهمين على مساءلة مجلس الإدارة واقتر اح الحلول المناسبة التي تساعد في تحسين جودة التقارير المتكاملة في جائحة كوفيد-19" قد حصلت على أقل فئل

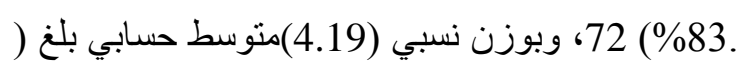

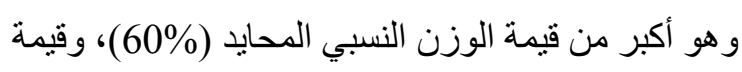
) وهي أكبر من 40.12) المحسوبة يساوي (T) ونتبار(

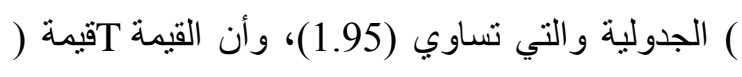

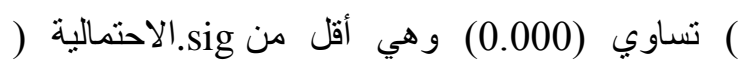
(0.05)، و هذا يدلل على أن شركات الاستثمار المدرجة في بورصة فلسطين تطبق آليات الحوكمة، لمساعدة المساهمين على مساءلة مجلس الإدارة خاصة في ظل لورئل جائحة كوفيد-19.

ـ تبين أن المتوسط الحسابي لجميع فقرات المجال يساوي \%) وهو أكبر من قيمة 65.82، وبوزن النسبي (4.13)( 
) لمعرفة منوسط درجة الاستجابة قد Tاختبار قيمة (

وصل إلى الدرجة المتوسطة وهي (3) أو لا لدى أفراد

ـ اختبار الفرضية الرابعة: "يوجد دور لتطبيق آليات

العينة، و النتائج موضحة في الجدول التالي:-

الحوكمة (دور أصحاب المصالح) في تحسين جودة التقارير المتكاملة في جائحة كوفيد-19"، وتم استخدام

جدول رقم (9) التحليل الإحصائي لفقرات الفرضية الرابعة

\begin{tabular}{|c|c|c|c|c|c|c|}
\hline الترتيب & $\begin{array}{l}\text { الاحتمالية } \\
\text { (القيمة } \\
\text { ).sig( }\end{array}$ & 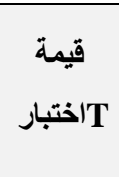 & النسبي & الانحراف & الحسابي & العبــــــــــــــــارات \\
\hline 4 & 0.000 & 9.23 & 82.33 & 0.79 & 4.12 & 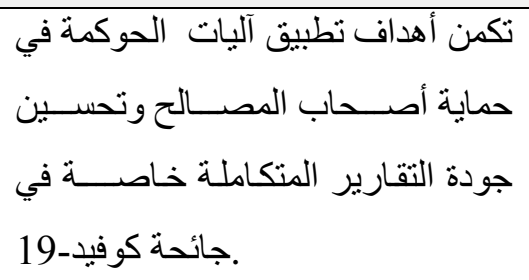 \\
\hline 5 & 0.000 & 10.49 & 81.40 & 0.67 & 4.07 & 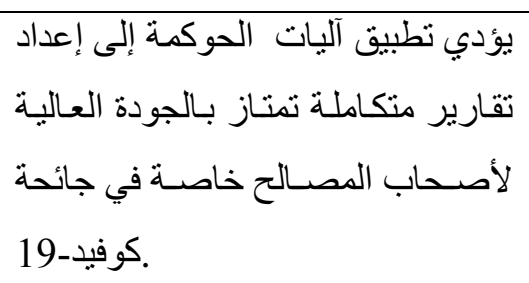 \\
\hline 6 & 0.000 & 12.41 & 83.26 & 0.61 & 4.16 & 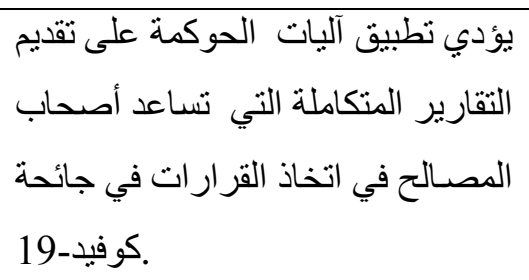 \\
\hline 3 & 0.000 & 7.67 & 79.07 & 0.82 & 3.95 & 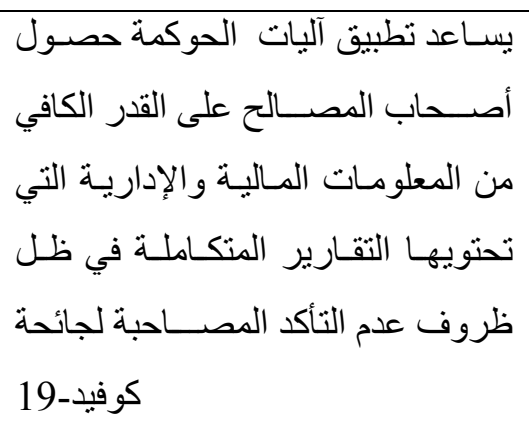 \\
\hline 2 & 0.000 & 8.08 & 80.47 & 0.83 & 4.02 & 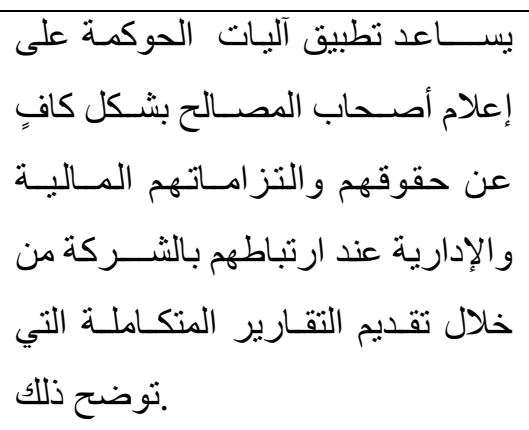 \\
\hline 1 & 0.000 & 7.64 & 80.93 & 0.90 & 4.05 & الالفـــــاح عن المعلومات المالية وغير \\
\hline
\end{tabular}




\begin{tabular}{|c|c|c|c|c|c|c|}
\hline & & & & & & 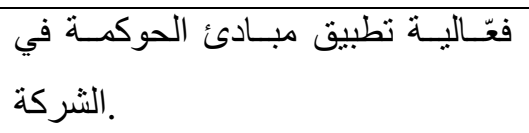 \\
\hline - & 0.000 & 12.44 & 81.24 & 0.56 & 4.06 & جميع الفقرات معاً \\
\hline
\end{tabular}


) الجدولية و التي تساوي (1.95)، وأن Tمن قيمة ( ) تساوي (0.000) و هي أقل sig.القيمة الاحتمالية ( من (0.05)، لذلك يعتبر المجال دالاً إحصائياً عند

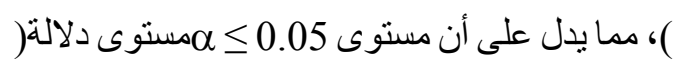

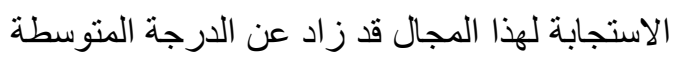
وهي (3)، و هذا يعني أن هناك مو افقة من قبل أفر اد العينة على فقر ات هذا المجال.

- نتيجة الفرضية: ووفقاً للجدول السابق وتحليل

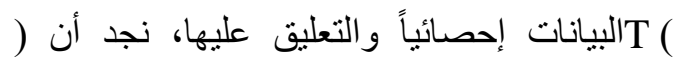
) المحسوبة، مما يعني رفض Tالجدولية أقل من ( الفرضية العدم، وقبول الفرضية البديل الذي ينص يُص على أنه "يوجد دور لتطبيق آليات الحوكمة (دور لئه أصحاب المصالح) في تحسين جودة التقارير المتكاملة في جائحة كوفيد-19".

ويرى الباحثان أن موافقة أفراد العينة بدرجة كبيرة على أنه يوجد دور لتطبيق آليات

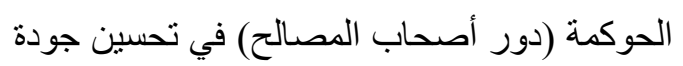
التقارير المتكاملة في جائحة كوفيد-19، وقد يعزى التول ذللك إلى أن شركات الاستثمار المدرجة في بورصة فلسطين تعترف في حدود إطار حوكمة الثركات

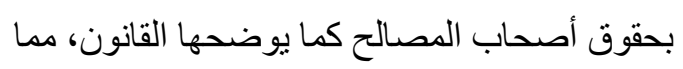

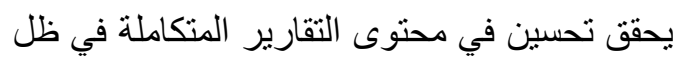
ظروف عدم التأكد المصاحبة لجائحة كورونا. لم تتفق نتائج هذه الفرضية مع نتائج أي در اسة، كما

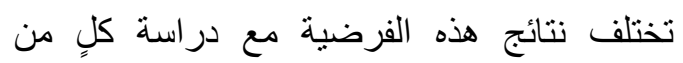
García-Sánchez, 2020) (Shaw, et al, 2020) ،(Atkins, et al, 2020) ‘(Foster, 2020) ‘(Izzo M.F., Fiori G., $2016 .($
يستنتج الباحثان من الجدول السابق رقم (9) ما يلي: - إن الفقرة رقم (6) التي تنص على "الإفصاح عن المعلومات المالية وغير المالية التي تحتويها التقارير

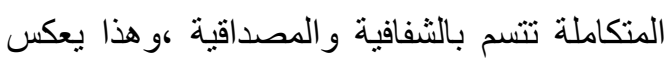

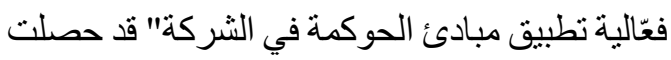
، وبوزن 4.05)على أعلى متوسط حسابي بلغ ( )

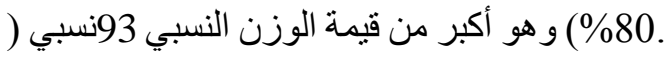
) المحسوبةT المحايد (60\%)، وقيمة اختبار( ) الجدولية T) وهي أكبر من قيمة (64.7يساوي (

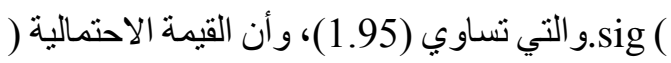
تساوي (0.000) وهي أقل من (0.05)، و هذا يدلل على أن شركات الاستتمار المدرجة في بورصي فلسطين تهنم بتقديم التقارير المتكاملة التي تحتوي على معلومات مالية وغير مالية، والتي تمتاز بالمصداقية و الثفافية، و هذا يعكس فعالية تطبيق آليات الحوكمة داخل هذه الثركات في ظل عدم التأكد المصاحبة لجائحة كوفيد-19.

- إن الفقرة رقم (3) التي تنص على "يؤدي تطبيق آليات الحوكمة على تقديم التقارير المتكاملة التي لتي لتحني تساعد أصحاب المصالح في اتخاذ القرارات في جائحة كوفيد-19" قد حصلت على أقل منوسط

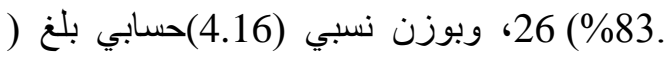
و هو أكبر من قيمة الوزن النسبي المحايد (60\%)، وبرن

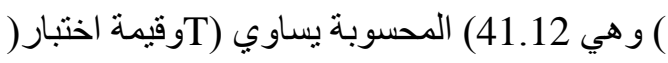

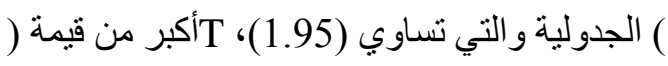

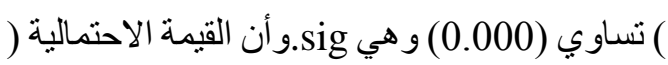
أقل من (0.05)، وهذا يدلل على وهي أن شركات الاستثمار المدرجة في بورصة فلسطين تقدم تقارير متكاملة لتمكين أصحاب المصالح من اتخاذ القرارات الرشيدة في ظل جائحة كوفيد-19.

ـ تبين أن المتوسط الحسابي لجميع فقرات المجال

\%) و هو 24.81، وبوزن النسبي (4.06)يساوي ( أكبر من قيمة الوزن النسبي المحايد (60\%)، وقيمة ولهابة

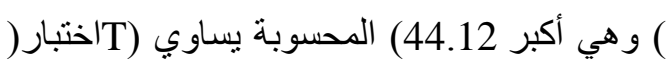


الحوكمة وتعزيز جودة التقارير المتكاملة في ظل جائحة كوفيد-19.

8. يوزع مجلس الإدارة في شركات الاستثمار المدرجة في بورصة فلسطين المسؤوليات الإتشر افية والتنفيذية التي تساعد على التنفيذ المحكم والفعال لتطبيق آليات الحوكمة، من أجل تعزيز جودة التقارير المتكاملة في جائحة كوفيد.19

9. يكفل تطبيق آليات الحوكمة في شركات الاستثمار المدرجة في بورصة فلسطين المعاملة المتكافئة لجميع المساهمين و المستثمرين، وحماية حقوقه، وتعزيز النزاهة و الثفافية عند إعداد التقارير المتكاملة التي وني تساعدهم في اتخاذ القرارات الهامة وخاصة المتعلقة بجائحة كو فيد-19.

10. تهنم شركات الاستثمار المدرجة في بورصة فلسطين بتقديم التقارير المتكاملة التي تحتوي على معلومات مالية وغير مالية والتي تمتاز بالمصداقية و الثفافية، وهذا يعكس فعالية تطبيق آليات الحوكمة داخل هذه الشركات في ظل عدم التأكد المصاحبة لجائحة كوفيد-19.

11. يساعد تطبيق آليات الحوكمة في شركات الاستثمار المدرجة في بورصة فلسطين على حصول أصحاب المصالح على القدر الكافي من المعلومات المالية و الإدارية التي تحتويها التقارير المتكاملة في ظل ظروف عدم التأكد المصاحبة لجائحة كوفيد-19.

\section{ثانياً: التوصيات:}

بناءً على النتائج السابقة يوصي الباحثان بالتوصيات

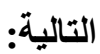

1. محاولة الاستفادة من المز ايا التي تحققها آليات الحوكمة والتوسع في تطبيقها من قبل إدارات شركات الاستثمار المدرجة في بورصة فلسطين، لما لها أهمية في تحسين جودة التقارير المتكاملة في ظل جائحة كوفيد-19. 2. حث شركات الاستثمار المدرجة في بورصة فلسطين على وضع إجر اءات و إرشادات عملية لمتابعة مدى التزام العاملين لديها بآليات الحوكمة وتطبيقها الفعلي وفقا لمتطلبات التشريعات و الجهات الرقابية.
النتائج والتوصيات:

أولاً: النتائج: النوان:

بناءً على التحليل الاحصائي توصل الباحثان إلى النتائج

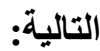

1. يوجد دور كبير لتطبيق آليات الحوكمة (مسئوليات مجلس الإدارة) في تحسين جودة التقارير المتكاملة في جائحة كوفيد-19، بمنوسط حسابي لجميع فقرات المجال يساوي (4.19)، وبوزن نسبي (79.83\%).

2. يوجد دور كبير لنطبيق آليات الحوكمة (أساس محكم وفعال لحوكمة الثركات) في تحسين جودة التقارير المتكاملة في جائحة كوفيد-19، بمنوسط حسابي لجميع فقرات المجال يساوي (4.01)، وبوزن نسبي .(\%80.39)

3. يوجد دور كبير لتطبيق آليات الحوكمة (حماية المساهمين و المستثمرين) في تحسين جودة التقارير المتكاملة في جائحة كوفيد-19، بمتوسط حسابي لجميع فقرات المجال يساوي (4.13)، وبوزن نسبي .$(\% 82.65)$

4. يوجد دور كبير لتطبيق آليات الحوكمة (دور أصحاب المصالح) في تحسين جودة التقارير المتكاملة في جائحة كوفيد-19، بمتوسط حسابي لجميع فقر ات المجال بساوي (4.06)، وبوزن نسبي (81.24\%).

5. يقوم مجلس الإدارة في شركات الاستثمار المدرجة في بورصة فلسطين بالتحديد الدقيق للمسئوليات و المهام بشكل جيد لتسهيل مهمة القائمين على الحوكمة لإنتاج تقارير

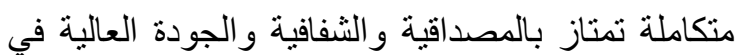
ظل جائحة كو فيد-19. 6. تطبق شركات الاستثمار المدرجة في بورصة فلسطين آليات الحوكمة، مما أدى إلى تفعيل سياسة الإفصاح و الثفافية للتقارير المتكاملة وخاصة في ظل جائحة كوفيد.19

7. يقوم مجلس الإدارة في شركات الاستثمار المدرجة في بورصة فلسطين بمتابعة نشاطات أقسام الرقابة المالية و الإدارية، مما أثر بشكل إيجابي على كفاءة ممارسة آليات 
مرتجى ، عمر شعبان (2019) ، مدى تطبيق

شركات المساهمة العامة المدرجة في بورصة فلسطين لقو اعد حوكمة الثركات و اثر ذللك على لئ تقريرها المالي باستخدام مدخل القيمة الاقتصادية المضافة ، كلية الاقتصاد و العلوم

$$
\text { الادارية ، جامعة الاز هر ، غزة . }
$$

الحياري ، عمر يوسف عبد الله ، (2017) ، اثر

تطبيق مبادئ حوكمة الشركات في تعزيز موثوقية التقارير المالية الصادرة عن الثركات الصناعية المساهمة المدرجة في سوق عمان المالي ، كلية الاعمال ، جامعة الثرق الاوسط

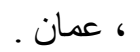

- Atkins, Jill Frances, Buchling, Michael, Dannielle, Cerboneand and Lange, Yvette. (2020). Accounting governance and integrated thinking in the context of COVID-19, See discussions, stats, and author profiles for this publication at: https://www.researchgate.net/publi cation $/ 341553718$.

- El-Mousawi, Hasan, Kanso, Hasan .(2020). Impact of COVID-19 Outbreak on Financial Reporting in the Light of the International Financial Reporting Standards (IFRS)-(An Empirical Study), Research in Economics and Management, Vol. 5, No. 2, 21-38.

- Escher, Luand. (2020). COVID-19 The Corporate Governance Perspecve, the Namibia Institute of Corporate Governance (NICG),
3. ضرورة حث شركات الاستثمار المدرجة في بورصة فلسطين على المزيد من الاهتمام بنشر ثقافة الالتز ام بإعداد التقارير المتكاملة ،و التي تعد أداة اتصال موجزة حول الكيفية التي تؤدى بها استراتيجية الشركات وحوكمتها وأدائها المالي وآفاقها المستقبلية في ظل عدم التأكد المصاحبة لجائحة كوفيد-19.

4. ضرورة قيام شركات الاستثمار المدرجة في بورصة فلسطين بمزييد من الاهتمام لتطبيق آليات الحوكمة لزيادة الثقة في التقارير المتكاملة ،بحيث تكون هذه التقارير شاملة ودقيقة وشفافة وتقدم المعلومة الملائمة من حيث الوقت المناسب لاتخاذ القرارات الرشيدة في ظل عدم التأكد المصاحبة لجائحة كوفيد-19.

5. نظراً للتغيرات التي أحدثنها جائحة كوفيد-19 في الآونة الأخيرة لابد من تزايد الاهتمام من قبل شركات الاستثمار المدرجة في بورصة فلسطين بتطبيق آليات الحوكمة من أجل إحكام الرقابة على الإدارة، ومنعها من لون لون استخدام سلطاتها وحثها على حماية حقوق المساهمين و المستثمرين و أصحاب المصالح، ووضع أساس محكم

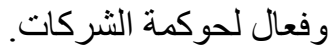

6. الاعتماد على المعلومات المالية وغير المالية التي تحتويها التقارير المتكاملة و التي تتسم بالثفافية والمصداقية في اتخاذ القرارات المالية والإدارية التي تساعد في تطبيق آليات الحوكمة بالثكل الصحيح في شركات الاستثمار المدرجة في بورصة فلسطين. 7. ضرورة أن تركز إدارات شركات الاستثمار المدرجة في بورصة فلسطين على زيادة التتقيف و الوعي لدى العاملين لديها بالأمور المتعلقة بالحوكمة والتقارير المنكاملة، من خلال عقد البرامج التدريبية والندوات المتخصصة بالحوكمة والتقارير المتكاملة.

8. حث الباحثين على إجراء المزيد من الدراسات والأبحاث في الحوكمة والتقارير المتكاملة وربطها بمعايير المحاسبة الدولية ،ودورها في تحسين جودة المعلومات التي تحتويها التقارير المتكاملة.

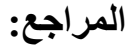


emerging economy. Meditari

Accountancy Research, Vol. 27, No.

$1,125-146$.

- Isabel-María García-Sánchez, Nicola Raimo, Arcangelo Marrone and Filippo Vitolla. (2020). How Does Integrated Reporting Change in Light of COVID-19? A Revisiting of the Content of the Integrated Reports, Sustainability 2020 ,

12,7605;doi:10.3390/su12187605, www.mdpi.com/journal/sustainabili ty.

- Izzo M.F., Fiori G. (2016). The Influence of Corporate Governance on the Adoption of The Integrated Report: A first Study on IIRC Pilot Programme. In: Mio C. (eds) Integrated Reporting. Palgrave Macmillan, London, https://doi.org/10.1057/978-1-13755149-8 9.

- JSE. (2020). Report back on the Proactive Monitoring of Financial Statements in 2019, Produced by the Issuer Regulation Department of the JSE,https://www.jse.co.za/currentc ompanies/issuerregulation/accounti ng-matters.

- ter-American Investment

Corporation (IDB Invest). (2019). Corporate Governance: COVID-19 and the Board of Directors, This https://www.tralac.org/documents/r

esources/covid19/countries/3628-

covid-19-the-corporate-

governance-perspective-nicg may2020/file.html.

- Evans, John. (2020). How to Save a Company from the Impact of COVID 19, South African Institute of Chartered Accountants (SAICA), https://www.bbrief.co.za/2020 04/20/how-to-save-a-companyfrom-the-impact-of-covid-19/.

- Foster, Richard. (2020). Critical insights into Covid-19's impact on organisations through the lens of the King IV Report, https://cdn.ymaws.com/gccbdi.org/r esource/resmgr/documents/covid19/Richard_Foster_-_Final_PDF_.pdf.

- García-Sánchez, Isabel-María, Raimo, Nicola , Arcangelo, Marrone, and Vitolla, Filippo. (2020). How Does Integrated Reporting Change in Light of COVID-19? A Revisiting of the Content of the Integrated Reports, Sustainability, vol. 12, www.mdpi.com/journal/sustainabili ty.

- Howard, M., W. Maroun, and R. Garnett. (2019). Misuse of nonmandatory earnings reporting by companies: Evidence from an 
Response,

https://www.pwc.com/us/en/library

/covid19/crisismanagement.html.

Shaw, Rajib, Kim, Yong-kyun, Hua, Jinling. (2020). Governance, technology and citizen behavior in pandemic: Lessons from COVID-19 in East Asia, Journal Pre proof, https://doi.org/10.1016/j.pdisas .2020 .100090 work has been licensed under

Creative Commons IGO,

Attribution-

NonCommercialNoDerivatives

license (CC-IGO BY-NC-ND 3.0

IGO

License),

http://creativecommons.org/license s/by-ncnd/3.0/igo/legalcode.

- Price, water, house, Coopers. (2020). COVID-19: Strategic Crisis 